\title{
PAN PARA EL CABILDO CATEDRAL DE BURGOS (1754-1760). HORNOS, PANADEO Y PRIVILEGIOS DE CLASE
}

\author{
Bread for Chapter Cathedral of Burgos (1754-1760). Ovens, Panadeo and Class Privilege \\ Francisco J. SANZ de La Higuera \\ IES «Torreblanca» (Sevilla) \\ sanzdelahiguera@gmail.com
}

Fecha de recepción: 20-IX-2012

Fecha de aceptación: 3-X-2012

\begin{abstract}
Resumen: El Cabildo Catedral de Burgos consideró, a partir de 1754, que era posible desligarse del sistema de abastecimiento de pan según el método de la «obligación», implantado en el municipio por el Concejo y la administración borbónica -con la «colaboración» de los vecinos de Arcos de la Llana y otros pueblos de los alrededores-, e instaurar su particular y propio método de hacer llegar el pan a las mesas de los prebendados catedralicios. Para ello, y en el derrotero urbano de permitir la instalación de hornos particulares en la ciudad de una manera más o menos libre, el Cabildo contrató a un panadero, con el que subscribió una "Escriptura para dar abasto de pan al Cavildo». Instalados los hornos en la calle La Calera, la experiencia, convergente con otras logísticas de productos esenciales -cacao y chocolate, carnero, vino, aceite, etcétera- controladas por la Mesa Capitular de la Catedral, acabó fracasando por la negligencia de los panaderos. En la práctica, esta propuesta tenía mucho de contestataria contra el gobierno y a favor de una autonomía capitular cada vez más amenazada por el Estado borbónico.
\end{abstract}

Palabras clave: Pan, Hornos, Panadero, Abastecimiento, Cabildo Catedral, Siglo XVIII.

AвsтRACт: The Chapter Cathedral of Burgos considered, from 1754, it was possible to withdraw from the bread supply system according to the method of «obligación», implemented in the municipality by the Council and the Borbonic administration -with the "collaboration» of the neighbors of Arcos de la Llana and other surrounding villages-, and establish its own particular method of getting the food to the table of the Cathedral prebendaries. For 
his reason, and in the urban course of allowing the installation of particular ovens in the city in a more or less free way, the Chapter hired a baker, who subscribed an «Escriptura para dar abasto de pan al Cabildo». Furnaces installed at La Calera street, the experience, coinciding with logistics of other essential products - cocoa and chocolate, sheep, wine, oil, etcetera- controlled by the Chapter Bureau of the Cathedral, ended in failure because of the negligence of the bakers. In practice, this proposal had a lot of contestation against the govermment and in favour of capitulate autonomy increasingly threatened by de Borbonic State.

Keywords: Bread, Ovens, Baker, Supplying, Chapter Cathedral, Eighteenth century.

\section{INTRODUCCIÓN, FUENTES DOCUMENTALES Y BIBLIOGRAFÍA}

"El Señor Capiscol significó avía llegado a su noticia averse echado por un Particular memorial a la Ziudad pidiendo se mandasen fabricar ornos y se le fazilitasen los Instrumentos nezesarios pues de este modo surttiría de Pan al Pueblo con más utilidad que la que oi se experimenta, en cuia considerazión no sería pensamiento mui estraño que teniendo V. S. Sittios donde poderse también hazer, se practicará lo mismo, logrando por estte medio probehería todos los Individuos del Cavildo de Pan de mejor Calidad y más varato» ${ }^{1}$. Estas palabras, pronunciadas en el seno del Cabildo de la Catedral de Burgos el día 28 de febrero de 1754, leían, y ponían voz, a los pensamientos de gran parte de los capitulares catedralicios, y no cayeron en saco roto. Ese mismo día, los asistentes al coro encargaron al susodicho Capiscol y al canónigo Quintana que examinaran «estte puntto con toda reflexión y [determinaran] qué era nezesario para el establecimiento de este proiectto, el Sittio para la construzción de los Ornos y gastto en la conduzción del trigo proporzionado para ello» ${ }^{2}$. Ambos prebendados recibieron el mandato de traer para el siguiente Cabildo una planificación exhaustiva «Sobre hazer ornos para hazer pan» ${ }^{3}$. Las, en algunas ocasiones, tensas relaciones del Cabildo Catedral con el Concejo y las turbias circunstancias por las que atravesaba la logística municipal del panadeo para la población de la ciudad de Burgos estimulaban la búsqueda de soluciones radicales y contestatarias, incluso en la institución eclesial de mayor rango de la ciudad.

Las circunstancias citadas proceden de una fuente documental atractiva como pocas, los Libros de Registro o Actas del susodicho Cabildo Catedral. De sus folios se extraen algunas de las vicisitudes que nos acompañarán a lo largo de estas páginas. En perfecta sintonía con ellos, traeremos a colación, también, documentos hallados entre

1 Archivo Capitular de la Catedral de Burgos. Actas Capitulares -en lo sucesivo ACCB. AC-. Libro de Registro 106. Cabildo del 28 de febrero de 1754, folio 686.

2 Ibidem. Se iniciaba, así, una experiencia que se pensaba exitosa y acabó siendo, a la postre, un rotundo fracaso. El «reflexionando lo traigan al Cavildo para su resolución» generaba un periplo de varios años en que los prebendados degustaron las hieles de una aparente libertad y de un presunto «liberalismo» que potenciaba la autonomía del Cabildo frente a los poderes borbónicos.

3 Presentaron al Cabildo un proyecto de Escritura, y las condiciones que postulaban indispensables, en ACCB. AC. LR 106. Cabildo del 26 de abril de 1754, folio 712. 
los Protocolos Notariales custodiados en el Archivo Histórico Provincial de Burgos ${ }^{4}$-en especial la "Escritura para dar abasto de pan al Cavildo de la Sta Yglesia Metropolitana», fechado el 13 de agosto de $1754^{5}$ - y, a modo de imprescindible complemento, las informaciones recopiladas en el Archivo Municipal de Burgos en lo tocante al abasto de pan a Burgos, sea a través de papeles sueltos como merced al rastreo de dicha problemática en las Actas de Gobierno y las Actas de Abasto del Concejo ${ }^{6}$. Del AMB procede igualmente la información sobre el número de «Horneros» o tiendas visitadas por los gestores municipales ${ }^{7}$ y los múltiples avatares y problemáticas que mantenía el Concejo con los pueblos de la «obligación» de abasto de pan a la ciudad ${ }^{8}$. Las Respuestas Particulares elaboradas al hilo de la gestación del Catastro de Ensenada posibilitan la reconstrucción de una perspectiva panorámica excelente sobre en qué situación se encontraba la logística del pan tanto en la propia ciudad de Burgos ${ }^{9}$ como en las localidades cercanas obligadas ${ }^{10}$ a suministrar ese bien esencial a los hogares e instituciones urbanos.

Sin pretender efectuar un estado de la cuestión, el acervo bibliográfico disponible nos acerca a una producción científica importante y nutritiva, en la que descuellan algunas obras de singular interés y gran calidad. Destacan, en especial, las propuestas de análisis de PALACIO ATARD, ESPADAS BURGOS, DOMÍNGUEZ ORTIZ, de CASTRO, BERNARDOS SANZ, GARCÍA MONERRIS y PESET ROIG, CASADO

4 Archivo Histórico Provincial de Burgos. Protocolos Notariales -en adelante citado como AHPB. PN-.

5 AHPB. PN. Juan Antonio Fernández Guilarte. Legajo 7019 (13 de agosto de 1754), folio 372.

6 Archivo Municipal de Burgos -AMB-. Actas de Gobierno (1700-1799) y Actas de Abastos (17711799).

7 AMB. Histórica. Véanse todas las citas de archivo en SANZ de la HIGUERA, Francisco, «De tiendas por Burgos 1750-1794)», en Investigaciones Históricas, 26, Valladolid, 2006, pp. 163-186.

8 AMB. Histórica. C 12-b-2 (1753-1754). Papeles varios sobre abasto de pan a esta Ciudad. HI-4914 (1755-1757). "Demanda de los Concejos y Vecinas de las Villa de Sarracín, Villariezo y Villagonzalo de Pedernales con los Concejos y Vecinos de la Villa de Ontoria de la Cantera y el lugar de Cubillo del Campo Sobre Que les vendan Leña y Hornija para cozer Pan». C 55/13 (1763) y C 83-16 (1749). "Escriptura de obligación y Convenio enttre esta villa de Arcos y la Ciudad de Burgos sobre el abasto de 375 fans de trigo». Las Actas de Gobierno están preńadas de información sobre las problemáticas de la logística del pan y el abasto a la ciudad.

9 Archivo de la Diputación Provincial de Burgos. Catastro de Ensenada. Respuestas Particulares -en lo sucesivo citado como ADPB. CE. RP-. Libros 344-349. Memoriales de Seglares y Eclesiásticos.

10 ADPB. CE. RP. Arcos de la Llana. Libro 112. Villagonzalo de Pedernales. Libro 2275. Sarracín. Libro 1939 y Villariezo. Libro 2418. 
o PERIS BARRIO para Madrid ${ }^{11}$. GUTIÉRREZ ALONSO ${ }^{12}$ y CUBILLO de la PUENTE ${ }^{13}$ para Valladolid y León, respectivamente. Véanse también los planteamientos de PÉREZ SAMPER en Barcelona ${ }^{14}$. CORTÉS PEŃA para Málaga ${ }^{15}$, ESTEBAN CASTILLO en lo tocante a Castellón y CREMADES GRIÑÁN, CARO LÓPEZ y

11 PALACIO ATARD, Vicente, «Algo más sobre el abastecimiento de Madrid en el siglo XVIII», en Anales del Instituto de Estudios Madrileños, 6, Madrid, 1970, pp. 253-175, PALACIO ATARD, Vicente, Alimentación y abastecimiento de Madrid en la segunda mitad del siglo XVIII, Madrid, Instituto de Estudios Madrileńos, Aula de Cultura, 1966 y PALACIO ATARD, Vicente, La alimentación de Madrid en el siglo XVIII y otros estudios madrileños, Madrid, Real Academia de la Historia 1998. ESPADAS BURGOS, Manuel, «Abasto y hábitos alimenticios en el Madrid de Fernando VII", en Cuadernos de Historia, Anexos de la Revista Hispania, 4, Madrid, pp. 237-289. DOMÍNGUEZ ORTIZ, Antonio, "El abasto de pan a Madrid por los pueblos circunvecinos», en II Jornadas de estudios sobre la provincia de Madrid, Madrid, 1980, pp. 700-703. de CASTRO, Concepción, El pan de Madrid. El abasto de las ciudades españolas del Antiguo Régimen, Madrid, Alianza Editorial, 1987. BERNARDOS SANZ, José Ubaldo, Trigo castellano y abasto madrileño. Los arrieros y comerciantes segovianos en la Edad Moderna, Salamanca, Junta de Castilla y León, 2003, BERNARDOS SANZ, José Ubaldo, No sólo de pan. Ganadería, abastecimiento y consumo de carne en Madrid (1450-1803), Madrid, Universidad Autónoma de Madrid, 1997 y BERNARDOS SANZ, José Ubaldo, "Libertad e intervención en el abastecimiento de trigo a Madrid durante el siglo XVIII», en MARIN, Brigitte y VIRLOUVET, Catherine (Dirs.), Nourrir les cités de Méditerranée, París, Maisonneuve \& Larose, 2004. GARCÍA MONERRIS, Ma Carmen y PESET REIG, José Luis, "Los gremios menores y el abastecimiento de Madrid durante la ilustración», en Moneda y Crédito, 140, Madrid, pp. 67-97. CASADO, Demetrio, "Algunos aspectos de la alimentación de Madrid», en Anales del Instituto de Estudios Madrileños, 3, Madrid, 1968, pp. 281-288 y PERIS BARRIO, Alejandro, "El abastecimiento de pan a Madrid en siglos pasados», en Revista de Folklore, 105, Madrid, pp. 75-78.

12 GUTIÉRREZ ALONSO, Adriano, Estudio sobre la decadencia de Castilla. La ciudad de Valladolid en el siglo XVII, Valladolid, Universidad de Valladolid, 1989, pp. 238-253 y GUTIÉRREZ ALONSO, Adriano, "Abastecimiento y consumo en Burgos durante el siglo XVIII: una primera aproximación», en Boletín de la Institución Fernán González (BIFG), 223, Burgos, 2001-2202, pp. 285-324.

13 CUBILLO de la PUENTE, Roberto, Comer en León. Un siglo de historia: 1700-1800, León, Universidad de León, 2000, pp. 188-212.

14 PÉREZ SAMPER, Ma de los Ángeles, «El pan nuestro de cada día en la Barcelona Moderna», en Pedralbes, 22, Barcelona, 2002, pp. 29-72 y PÉREZ SAMPER, Ma de los Ángeles, Mesas y cocinas en la España del siglo XVIII, Oviedo, Trea, 2011.

15 CORTÉS PEÑA, Antonio Luis, "Una petición de los panaderos malagueños en el siglo XVIII», en Hespérides, Actas del VIII Congreso de Profesores-investigadores, Baena, 1990, pp. 261-265. 
ROMÁN CERVANTES en el territorio murciano ${ }^{16}$. Para Ibiza, DEMERSON ${ }^{17}$. Para Almería, véase GÓMEZ CRUZ, REYES MESA y RUBIO GANDÍA ${ }^{18}$ y SOLA AYAPE para Pamplona ${ }^{19}$. Véanse también MEJÍA CARRILLO y CALVENTO MARTÍNEZ para la América colonial ${ }^{20}$.

\section{LA LOGÍSTICA DEL PAN EN LA CIUDAD DE BURGOS}

El análisis de en qué circunstancias se hallaban los panaderos y horneros de Burgos y de los pueblos suministradores obligados conlleva, en el fondo, una contestación lo más objetiva posible al interrogante esencial, es decir, por qué el Cabildo Catedral decidió independizarse en lo tocante a asegurar a sus componentes el acceso fluido y sostenido al pan. El panorama que se percibe entre los fabricantes de pan de la ciudad era tan mediocre y deprimente como el que, presumiblemente, atisbaban cotidianamente los prebendados catedralicios. Y es que elaborar pan no era, en absoluto, signo de bienestar económico sino más bien síntoma de un diagnóstico terrible. Los panaderos y horneros de la ciudad, y de los pueblos sujetos a la obligación de fabricar pan para los vecinos urbanos, vivían en condiciones difíciles y caracterizadas, en su inmensa mayoría, por ser hogares paupérrimos y con ínfimos niveles de renta y fortuna.

La ciudad de Burgos, a mediados del siglo XVIII, en 1751, contaba entre sus vecinos con 41 hogares en los que sus componentes desarrollaban habitualmente quehaceres profesionales dados a la fabricación de pan. 29 de tales hogares eran panaderos o

16 ESTEBAN CASTILLO, Tomás, «El molino harinero. El horno de pan cocer. Las panaderías. Condiciones de sus arrendamientos por los particulares y el Ayuntamiento en Castellón (siglo XVIII)», en Estudis Castellonencs, 7, Castellón, 1996-1997, pp. 613-647. CREMADES GRIÑÁN, Carmen Ma, Alimentación y consumo en la ciudad de Murcia durante el siglo XVIII (1701-1766), Murcia, Universidad de Murcia, 1984, pp. 60-76. CARO LÓPEZ, Ceferino, "Los precios del pan en Murcia en el siglo XVIII", en Revista de Historia Económica, 1, Madrid, 1987, pp. 31-48 y CARO LÓPEZ, Ceferino, "Las oscilaciones del precio del trigo en una ciudad del Levante: el caso de Murcia, 1675-1800», en Revista de Historia Económica, 2, Madrid, pp. 247-264 y ROMÁN CERVANTES, Cándido, "Abastecimiento cerealístico en la Cartagena de principios del siglo XVIII (1725-1740)», en Cuadernos de Historia Moderna y Contemporánea, 8, Madrid, 1987, pp. $109-126$.

17 DEMERSON, Paula y Jorge, «El problema del pan en la Ibiza del siglo XVIII», en Dieciocho, 22/2, 1999, pp. 291-306.

18 GÓMEZ CRUZ, Manuel, REYES MESA, José Ángel y RUBIO GANDÍA, Miguel Ángel, «El abastecimiento de pan a la ciudad de Almería en el siglo XVIII», en Hespérides: Anuario de investigaciones, 3, Sevilla, 1995, pp. 357-365.

19 SOLA AYAPE, Carlos, Abasto de pan y politica alimentaria en Pamplona (Siglos XVI-XX), Pamplona, Universidad Pública de Navarra, 2002.

20 MEJÍA CARRILLO, Yolanda, «Panaderías coloniales del siglo XVIII», en Seguilao, 4-5, 1993, pp. 66-71 y CALVENTO MARTÍNEZ, Ma del Carmen, «El abastecimiento de pan en la ciudad de México (1700-1770)", en Actas del XXXVI Congreso internacional de Americanistas, Sevilla, 1966, p. 351-364. 
panaderas $^{21}(70.7 \%)$ y 12 hogares eran horneros u horneras ${ }^{22}(29.3 \%)$. No todos se dedicaban en exclusiva al panadeo, de forma que, como se comprueba en el CUADRO I, muchos hogares compatibilizaban -con el concurso sobre todo de las mujeres- la fabricación de pan con otras profesiones. 32 de ellos estaban comandados por hombres (78.1\%) y $9(21.9 \%)$ tenían a su cabeza a una mujer, en general viudas, analfabetas, de edad madura y empeñadas en sacar a sus vástagos adelante con niveles de renta paupérrimos -en la práctica, con alcances anuales e ingresos procedentes de la fabricación de pan que resultaban la mitad de lo obtenido por los hombres ${ }^{23}$.

A la panadería se dedicaban en exclusiva un $39.1 \%$ de los susodichos hogares, si bien existe -véase CUADRO I- un notable contraste entre hombres y mujeres. Estaban volcados a la fabricación de pan, como actividad única, el $28.2 \%$ de los varones -que como veremos a continuación compatibilizaban tales labores con otros empleos- y el $77.8 \%$ de las mujeres. Aunque la mayoría era propietario de su horno también nos topamos con algunos, como por ejemplo, Francisco Asenjo que indicó en su memorial catastral que pagaba de alquiler al dueño 50 reales al año. De su trabajo obtenía 4 reales al día que suponía, aproximadamente, 1.200 reales/año -cantidad de la que es preciso descontar la citada renta del horno y el salario de una muchacha de 12 años a quien pagaba un ducado/año por la ayuda laboral-. Francisco Asenjo era analfabeto y su hogar, un (4c)4 según la terminología de Laslett y la Escuela de Cambridge ${ }^{24}$, se acogía en unos más que estrechos y limitados $35.9 \mathrm{~m}^{2}$ de suelos útiles para la convivencia ${ }^{25}$. El inventario de bienes que se le efectuó en 1763, al hilo de su fallecimiento, arroja una cantidad, 4.367 1/2

21 Los panaderos y panaderas eran profesionales de la fabricación de pan que trabajaban para entidades o instituciones urbanas como el Concejo (Panadería), el Sepulcro o el Regimiento de Inválidos de Cataluña.

22 Los horneros u horneras recibían en sus hornos a individuos cercanos, a quienes cocían algunas fanegas de trigo y entregaban hogazas de pan.

23 Véase las reflexiones de RIAL GARCÍA, Serrana, Las mujeres en la economía urbana del Antiguo Régimen: santiago durante el siglo XVIII, La Coruña, Edicios do Castro, 1995 y RIAL GARCIA, Serrana, "Las mujeres «solas» en la sociedad semi-urbana gallega del siglo XVIII», en Obradoiro de Historia Moderna, 8, Santiago, 1999, pp. 169-197 y RAMIRO MOYA, Francisco, Mujeres y trabajo en la Zaragoza del siglo XVIII, Zaragoza, Prensas Universitarias de Zaragoza, 2012, pp. 197-200.

24 Véanse, entre otras muchas, LASLETT, Peter, El mundo que hemos perdido, explorado de nuevo, Madrid, Alianza Universidad, 1987; GARCÍA GONZÁLEZ, Francisco, La Sierra de Alcaraz en el siglo XVIII. Población, familia y estructura agraria, Albacete, Instituto de Estudios Albacetenses «Don Juan Manuel», 1998 y TORRES SÁNCHEZ, Rafael, «Estructura familiar y grupo doméstico en la España del siglo XVIII», en Cuadernos de Investigación Histórica, 13, Madrid, 1990, pp. 189-215. (4c)4 significa un hogar extenso o ensanchado con un matrimonio, con o sin hijos, o un viudo o una viuda, con hijos, y uno o más criados o criadas.

25 SANZ de la HIGUERA, Francisco, «Familia, hogar y vivienda en Burgos a mediados del siglo XVIII: entre cuatro paredes, compartiendo armarios, camas, mesas y manteles», en Investigaciones Históricas, 22, Valladolid, 2002, pp. 165-212. Para Francisco Asenjo, ADPB. CE. RP. Libro 344, folio 876 . 
reales generados en el trabajo en el horno, cantidad que le permitía abonar la renta de los entresuelos en que albergaba su hogar y mantener, con gran precariedad, a sus hijos y al pollino que le ayuda en sus quehaceres laborales ${ }^{27}$.

Son éstos dos ejemplos de un panorama desolador que se trocaba en trágico si traemos a colación a Matías Maeso, un hombre de edad avanzada -60 años a mediados de 1751-, "corto de vista y casi ciego» ${ }^{28}$, que, a duras penas, manejaba dos fanegas de pan cocido para vender, ayudado por una pollina "para llevarlo a moler». La estrechez no sólo afectaba a las dimensiones del cuarto-casa que ocupaban, en régimen de alquiler ${ }^{29}, 16.5$ $\mathrm{m}^{2}$, sino a su existencia al completo. Aunque no sabía leer ni escribir, un testigo, a su voz, escribió que "Dezimos como somos unos pobres sin hazienda de raiz ni cassa ni bienes muebles sino que la Cama donde marido y mujer Dormimos» ${ }^{30}$. Mejor ambiente encontramos en el hogar de Pedro Viguer, un panadero de origen francés y extracción nobiliar, colocado al frente de un hogar múltiple, un (5b)7, por la confluencia simultánea, en el interior de un inmueble propiedad del Colegio de la Doctrina de Valladolid -dado en alquiler por 26 ducados/año-, de dos núcleos familiares. Pedro Viguer acogía en corresidencia al matrimonio formado por Miguel López, relojero, con su hija Francisca. El «trato de Panadería», en el que se reguló una ganancia anual de 660 reales -1.100 según el propio Viguer-, junto con los 1.000 reales del relojero -1.650 según Miguel López-, posibilitaban un útil anual al hogar de casi 1.400 reales, descontados los 286 reales del arrendamiento, que permitía vivir con cierta dignidad, circunstancia no exenta de problemas. Pedro Viguer declaró en su memorial -tanto el panadero francés como el relojero, su yerno, sabían escribir ${ }^{31}$ - «... no tener criado ni criada por no ttener con qué mantenerlos a causa de lo poco que da de si dicho oficio, y de dhos Zien ducados es necesario salga para el alimento y vestuario para ttodo lo que se ofrece en casa». La casa, de tres altos, disponía de 7 cuartos, 1 sala, 4 cocinas, 2 corredores más arriba, un soleador, «un aposento para la ofizina deel orno», una caballeriza -de $11.6 \mathrm{~m}^{2}-\mathrm{y}$ un patio de $76.1 \mathrm{~m}^{2}$. Los

211-242 y VIGLIONE ARRASTIA, Hebe M. L., «Familias sin hombres: mujeres jefas de hogar en el Virreinato del Río de la Plata. Pago de los Arroyos, provincia de Santa Fe, Argentina», en Temas Americanistas, 20, 2008, pp. 92-109.

27 ADPB. CE. RP. Libro 345, folio 761.

28 SANZ de la HIGUERA, Francisco, «Aproximación a los problemas de vista y el uso de anteojos en el Burgos de mediados del XVIII", en El Futuro del Pasado: Revista electrónica de historia, 3, Salamanca, 2012, pp. 371-401.

29 Pagaba 22 reales al ańo, lo que suponía detraer de sus ingresos una cantidad equivalente al $6.7 \%$.

30 SANZ de la HIGUERA, Francisco, «Pajas, catres, cujas, camas, ... El lecho cotidiano en el Antiguo Régimen: Burgos (1740-1780)», en Cuadernos de Investigación Histórica, 26, Madrid, 2009, pp. 435-499 y SANZ de la HIGUERA, Francisco, «Evolución de los lechos cotidianos y los menajes nocturnos en el XVIII burgalés", en Cuadernos de Investigación Histórica, 28, Madrid, 2011, pp. 389-431.

31 Véase SANZ de la HIGUER, Francisco, «La medida del tiempo en Burgos: Relojes a mediados del siglo XVIII», en Historia Social, 67, Valencia, 2010, pp. 23-49. 
26 ducados del alquiler permitían disponer de $937.7 \mathrm{~m}^{2}$, una auténtica enormidad al alcance de muy pocos hogares burgaleses ${ }^{32}$.

Lo común, sin embargo, era, entre los fabricantes de pan, la precariedad económica, aunque sin caer en el más absoluto deterioro paupérrimo, y la enfermedad. Andrés Arribas firmó su memorial, denunciando ser un «Panadero pobre e impedido por una enfermedad». Sus volúmenes de negocio eran muy limitados y, en consecuencia, sus ganancias escasas ${ }^{33}$. Varios ejemplos, sacados de algunos maravillosos memoriales, nos ponen tras la pista de lo reducida que era la capacidad de producción. Manuel Arce, de 21 años (1751), se ganaba su sustento con sus quehaceres en el «trato de Panadería» en el que "cueçen todas las Semanas seis fanegas de trigo»" ${ }^{34}$. La viuda Manuela Arnaiz, de 28 años de edad, "cueçe todas las semanas seis fanegas de trigo»" ${ }^{5}$. Ángela González, también viuda y de edad más avanzada (46 años), cocía 8 fanegas de trigo/semana ${ }^{36}$. Francisca Miguel repetía el modelo - viuda, analfabeta, entrada en años (tenía 50 a mediados de 1751) - y en el «trato de Panadería» daba curso a entre 6 y 8 fanegas de trigo por semana, que les permitía obtener unos ingresos de 600 reales/año -cantidad de la que se detraían 101 reales del alquiler de la vivienda-. En conclusión, «No se saca para comer» ${ }^{37}$.

Teresa Pérez, viuda de 61 años y también analfabeta, encargó que se dijera que «Declaro ganar la vida en el exercicio de la panadería, para la qual tengo en mi asistencia una Criada que me ayuda de noche y de día quando se ofrece, la doi de Salario en Cada un año ochenta y ocho reales Vellón» ${ }^{38}$. José García, Manual Sevilla y Vicente Pardo coincidieron, entre 1749 y 1753, en dedicar sus actividades laborales a ser los panaderos de la tropa de inválidos. De sus manos salía el «pan de munición de los soldados del Reximiento de Inválidos de Cataluña» (RIC) ${ }^{39}$. José García, de 23 años de edad, contaba con el auxilio de «un pollino de trabajo para llevar el pan» al cuartel del RIC, y, a la postre, era un empresario que generaba trabajo para un hornero -al que pagaba 3 hogazas por cada carga de pan-, una amasadora y una calentadora -que percibía una hogaza por cada

32 ADPB. CE. RP. Libro 347, folios 37-38 y 346, folio 248. Entre las dependencias del inmueble que tenían arrendado -pagaban por él 286 reales/año al Colegio de la Doctrina de Valladoliddestaca un "aposento» a modo de "ofizina deel orno», sito en el entresuelo, al lado de la caballeriza. ADPB. CE. RP. Libro 344, folio 58. ADPB. CE. RP. Libro 346, folio 112. ADPB. CE. RP. Libro 346, folio 117. ADPB. CE. RP. Libro 344, folio 173. ADPB. CE. RP. Libro 344, folio 885. ADPB. CE. RP. Libro 347, folios 456-457.

39 SANZ de la HIGUERA, Francisco, «Alojamiento de tropas en Burgos a mediados del siglo XVIII. Cuarteles, alquileres y hospitales para el Regimiento de Inválidos de Cataluña (1748-1753)», en Milicia y Sociedad ilustrada en España y América (1750-1800), Vol. I, Sevilla, 2003, pp. 335-360 y SANZ de la HIGUERA, Francisco, «Aproximación al impacto de los Reales Ejércitos en el Burgos de mediados del Setecientos», en Historia Militar, Revista Digital, Valencia, 2011, pp. 1-22. 
carga procesada- ${ }^{40}$.

Entre quienes, además de la panadería, ejercían otros trabajos, descuellan aquellos hogares en que él practicaba el ejercicio de la agricultura y ella se volcaban en la fabricación de pan y en las labores domésticas. En casa de Antonio Ruiz se cocía todas las semanas cuatro fanegas de comuña, que redituaban 500 reales/año, a lo que se añadían algunos reales más procedentes de la labranza y el alquiler de su fuerza de trabajo como jornalero agrícola ${ }^{41}$. A Juan Ruiz, panadero y labrador, se le computan, en el momento de su fallecimiento bienes por valor de 33.488 reales -en su nivel de rentas se palpaba la precariedad con 500 reales de ingresos y 236 reales de útil, tras abonar el alquiler de su vivienda, que le detraían 264 reales, es decir, el $52.8 \%$ de su economía doméstica- ${ }^{42}$. Bastante más sostenible era la existencia del también panadero y labrador Blas Rangel. Los 1.446 reales que se le pueden adjudicar de útil anual ${ }^{43}$ están en sintonía con los 34.314 reales de su IPM ${ }^{44}$. De ese mismo tenor eran los parámetros económicos de Matías Delgado, quien "compra una Carga de trigo y la vende cocida», quehaceres que generaban 1.500 reales/año en el pan y un ingreso neto de 454 reales por el cultivo de sus tierras ${ }^{45}$. Mayor precariedad hallamos en casa de Manuel Moreno Valencia. Él, dado a la labranza, únicamente alcanzaba la miseria, con unas ganancias netas frustrantes -175 reales/año-, mientras que su cónyuge, panadera, que «cuece dos cargas de trigo a la Semana», daba al hogar un rendimiento cercano a los 500 reales/año ${ }^{46}$. Del mismo tenor son las ocurrencias del hogar conformado por Francisco Fernández y Águeda Barriocanal. Él, esquilador, obtenía un alcance anual de, aproximadamente, 1.600 reales -100 ducados/año decía en su memorial, corregido por los peritos catastrales-, complementados con los 500 reales aportados por la mujer, ocupada "en el oficio de Panadera, por no alcanzar mi oficio a pagar todos los gastos cotidianos de casa» ${ }^{47}$. Rodeados como estaban por pobres de solemnidad e hilanderas, jornaleros y panaderos-labradores ${ }^{48}$, su nivel

40 José García en ADPB. CE. RP. Libro 345, folio 701. Manuel Sevilla en ADPB. CE. RP. Libro 346, folio 208 y Vicente Pardo en ADPB. CE. RP. Libro 346, folio 211. Su marcha en 1753 dejó a quienes les había suministrado pan, aguardientes y otros productos esenciales de consumo en una situación muy difícil, que no fue paliada por el acantonamiento en Burgos de nuevos Regimientos.

41 ADPB. CE. RP. Libro 344, folio 179.

42 ADPB. CE. RP. Libro 347, folio 582 y AHPB. PN. Gregorio Padrones. Legajo 7139 (3 de octubre de 1786), folios 803-817. Tras las "Quentas y particiones» de sus bienes, cada uno de sus siete herederos recibió 4.955 reales. ADPB. CE. RP. Libro 344, folios 470-472.

44 AHPB. PN. Ángel Arnaiz. Legajo 7165 (18 de febrero de 1760), folios 344-354.

45 ADPB. CE. RP. Libro 346, folio 140.

46 ADPB. CE. RP. Libro 346, folio 448.

47 ADPB. CE. RP. Libro 344, folios 958-959.

48 En San Román tenían su vivienda otros panaderos y horneros ya citados, entre ellos Blas Rangel, Matías Delgado, Martín Díez o Juan Pesquera. 
de vida relacional era discreto pero no paupérrimo ni marcado por la postración y la enfermedad ${ }^{49}$.

Los horneros y horneras, fuera en exclusiva o asociada dicha actividad a otros quehaceres profesionales, eran hombres en el $91.7 \%$ de los casos. Nos topamos con individuos paupérrimos, como Domingo Pardo, situado al límite de la pobreza de solemnidad, quien alcanzaba únicamente 200 reales con su horno de pan por la "poca experiencia en el oficio» ${ }^{50}$-Ángela Martínez no estaba mucho mejor ${ }^{51}-$, y otros más afortunados, como Manuel Páramo, hornero de 2.000 reales, además de labrador, que se dedicaba a «cocer para las panaderías de la ciudad», lo cual le permitía alcanzar un útil anual elevado ${ }^{52}$. Francisco Sáez de Extremiana nos ofreció -sabía leer y escribir- un memorial catastral auténticamente sabroso. Por lo tocante al pan, indicó que se ejercitaba «en el tráfico de un orno que mantengo de todo lo necesario para Cozer pan, donde concurren Diferentes personas (...) y de dho trabajo y gasto de orno se me surtirán Como Ciento y cinquenta Ducados de Vellón (aunque se me paga en pan cozido)». Su industria panadera -contaba con la ayuda de un hijo de 14 años- quedaba complementada con los tratos de la labranza que desarrollaba habitualmente. Llevaba en renta diferentes tierras de varios propietarios. Sembraba entre 13 y 14 fanegas de todo pan y su producción eran 70 u 80 fanegas «con huebras ajenas y obreros del pueblo, por ser cojo y no poder trabajar por siin ${ }^{53}$.

María Josefa Ibeas encarna la figura de la viuda, entrada en años -52 a mediados de 1751-, responsable de un hogar, un (3d)4, que vio fallecer al cabeza de familia, maestro batidor de oro, lo que generó, como era habitual en las ciudades preindustriales, que "por aber quedado Pobres y Mantenerse Únicamente con suma estrechez del trabaxo y labor de ylar y hazer algunas Medias, tiene ofrecida y dada ynformazión de Pobreza [de solemnidad] en dha Caussa, a fin de que se les ayude y Defienda por Pobres», a lo cual unía algunos quehaceres para la fabricación de $\operatorname{pan}^{54}$. La precariedad de la hornera Maria Josefa contrasta con la mejor situación de Miguel Mayor, que, a fuerza de fabricar pan y cultivar algunas tierras, mantenía su hogar. Para ello disponía de un "Horno en casa donde van a

49 Paupérrimos, y sumidos en la estrechez, la postración y la enfermedad estaban todos aquellos hogares con alcances anuales inferiores a 300 reales. Eran quienes podían "consumir poco de poco». Véase MORENO CLAVERÍAS, Belén, "Pautas de consumo y diferenciación social en El Penedés a fines del siglo XVII. Una propuesta metodológica a partir de inventarios sin valoraciones monetarias», en LLOPIS, Enrique, TORRAS, Jaume y YUN, Bartolomé (Eds.), El consumo en la España pre-industrial, Revista de Historia Económica, No extraordinario, Madrid, 2003, pp. 230-232 (207245.

50 ADPB. CE. RP. Libro 344, folio 712.

51 ADPB. CE. RP. Libro 344, folio 182. Viuda, analfabeta, constreñida en un hogar múltiple y escaso espacio ( $51.7 \mathrm{~m} 2$ de suelos útiles para la convivencia), sus ingresos no superaban los 250 reales/ año.

52 ADPB. CE. RP. Libro 346, folios 109-110.

53 ADPB. CE. RP. Libro 344, folios 829-831.

54 ADPB. CE. RP. Libro 346, folio 236. 
cocer quatro labradores pan para el consumo de su casa, y también algún que otro pobre cueçe una fanega de pan. Cada uno deja una hogaza de pan». 700 reales/año era la traducción de sus desvelos en este terreno productivo. La labranza la llevaba en mancomún con su padre, Mateo Mayor. Indica a este respecto que «el modo de trabajar las dhas heredades es valiéndome de buscas labranzas, pagándoles su jornal, porque yo no tengo labranza con que poder cultivarlo" ${ }^{55}$.

José Lozano, hornero y labrador, resume el empeño de estos burgaleses metidos en la harina de fabricar los cereales y cocer y vender el pan. Al horno de su casa acudían «ventureramente caseras a cocer pan», lo que le dejaba anualmente, más o menos, 100 reales de útil. Una criada que tenía contratada para el manejo del horno percibía de salarios 9 ducados al año. En sus quehaceres campesinos, sembraba 20 fanegas de todo pan, las cuales producían entre 100 y 140 fanegas. 28 fanegas pagaba de renta a los propietarios de las tierras, entre 10 y 14 fanegas le suponía diezmo y 60 fanegas de cebada las dedicaba al alimento de los ganados - un par de rocines y un caballo pequeño-. Una vez pagados los 50 obreros que se encargaban de cardar, excavar, sembrar, sallar y segar, le quedaban aproximadamente 1.100 reales, "que regulado todo no alcanzaba para el mantenimiento de la familia» ${ }^{56}$.

En resumen, si efectuamos una análisis de los parámetros esenciales de los panaderos y horneros de Burgos en función de sus declaraciones o memoriales catastrales -véase CUADRO II-, nos topamos con unos hogares con economías en difícil equilibrio, con un talante basculado más hacia la pobreza agónica que hacia la riqueza tranquila, con promedios de edades similares a los de otras categorías socio-profesionales, dimensiones de las viviendas alrededor de la media de la ciudad, en el entorno de los $114 \mathrm{~m}^{2}$, y niveles de alfabetización nulos en las mujeres y escasos en los hombres. Un contraste rápido y perspicaz con los índices de la ciudad y sus distintos grupos humanos -véase CUADRO III- despeja, a mi juicio, cualquier duda a este respecto. Los panaderos y horneros de Burgos eran pecheros con niveles económicos y perfiles humanos no demasiado paupérrimos -su trabajo les costaba- pero lejanos, en todo caso, de los más afortunados de la sociedad burgalesa de Antiguo Régimen, a quienes proporcionaban el pan en condiciones ventajosas. La fabricación de pan no proporcionaba niveles agradables y cómodos de vida a los hogares implicados en tales cometidos. No se vivía de manera brutal en el inframundo de la pobreza de solemnidad pero tampoco se alcanzaba un estatus de vida confortable ni sosegado ni apacible. Cada noche las llamas de los hornos les recordaban que sus existencias pendían de un hilo, fácilmente rompible y preñado de enfermedades y muerte.

55 ADPB. CE. RP. Libro 346, folios 88-89.

56 ADPB. CE. RP. Libro 345, folio 623. 


\section{CUADRO II}

Parámetros vitales de los fabricantes de pan en Burgos (1751)

\begin{tabular}{|c|c|c|c|c|c|c|c|}
\hline & & & & HOMBRES & & & \\
\hline & $\mathrm{N}^{\circ}$ & $\%$ & Útil/@ (1) & Útil Pan (2) & Edad (3) & Firma (4) & M2Hogar (5) \\
\hline Panaderos & 21 & 65.6 & 982 & 823 & 39.5 & 23.8 & 156.5 \\
\hline \multirow[t]{3}{*}{ Horneros } & 11 & 34.4 & 1000 & 746 & 40.5 & 27.3 & 130.8 \\
\hline & & & & MUJERES & & & \\
\hline & $\mathrm{N}^{\circ}$ & $\%$ & Útil/@ (1) & Útil Pan (2) & Edad (3) & Firma (4) & M2Hogar (5) \\
\hline Panaderas & 8 & 88.9 & 447 & 519 & 45.5 & 0 & 164.1 \\
\hline \multirow[t]{3}{*}{ Horneras } & 1 & 11.1 & 226 & 150 & 51 & 0 & 51.7 \\
\hline & & & & TOTAL & & & \\
\hline & $\mathrm{N}^{\circ}$ & $\%$ & Útil/@ (1) & Útil Pan (2) & Edad (3) & Firma (4) & M2Hogar (5) \\
\hline Panaderos & 29 & 70.7 & 835 & 739 & 41.5 & 10.3 & 158.6 \\
\hline Horneros & 12 & 29.3 & 935 & 696 & 41.5 & 13.6 & 124.2 \\
\hline \multicolumn{8}{|c|}{ (1) Alcance anual del hogar: Ingresos brutos menos gastos habituales. En reales. } \\
\hline \multicolumn{8}{|c|}{ (2) Alcance anual gestado en los hornos. En reales de vellón. } \\
\hline (3) Edad media. & & & & & & & \\
\hline \multicolumn{8}{|c|}{ (4) Porcentaje de titulares del hogar que rubricaron el memorial catastral. } \\
\hline (5) Metros cuadr & dos & or hos & gar (promec & & & & \\
\hline
\end{tabular}

\begin{tabular}{|c|c|c|c|c|}
\hline \multirow[t]{2}{*}{ CUADRO III } & \multicolumn{4}{|c|}{ Parámetros esenciales del hogar burgalés } \\
\hline & Útil/@(1) & Edad (2) & M2Hogar (3) & Firma (4) \\
\hline Fabricantes de pan & 864 & 41 & 148.5 & 19.5 \\
\hline Panaderos & 835 & 41 & 158.6 & 17.2 \\
\hline Horneros & 935 & 41 & 124.2 & 25 \\
\hline Ciudad (Burgos) & 1496 & 46.5 & 114.1 & 37.3 \\
\hline Artesanos & 1476 & 42.5 & 114.6 & 43.5 \\
\hline Clérigos & 4231 & 45.5 & 245.1 & 100 \\
\hline Hilanderas & 204 & 53 & 49.8 & 17.5 \\
\hline Jornaleros & 279 & 44 & 50.1 & 16.1 \\
\hline Comerciantes & 4294 & 47 & 237.4 & 25.8 \\
\hline Burócratas & 4169 & 42.5 & 287.7 & 77.8 \\
\hline Servicios Públicos & 1493 & 46.5 & 142.5 & 94.8 \\
\hline Nobles rentistas & 21301 & 46 & 1081.9 & 63.3 \\
\hline Militares & 2258 & 50.5 & 71.2 & 98.6 \\
\hline Tropas & 548 & 51 & 10.9 & 1.5 \\
\hline \multicolumn{5}{|c|}{ (1) Alcance anual (ingresos brutos - gastos) en reales de vellón. } \\
\hline \multicolumn{5}{|c|}{\begin{tabular}{l|l|l|} 
(2) Promedio de edades. & \\
\end{tabular}} \\
\hline \multicolumn{5}{|c|}{ (3) Metros cuadrados por hogar (dimensiones de la vivienda). } \\
\hline (4) Porcentaje de me & horiales firn & hados. & & \\
\hline
\end{tabular}


Los panaderos y horneros de Burgos no residían, salvo excepciones muy puntuales, en el interior del recinto amurallado ni en las calles y plazas de mayor fortuna económica. Tenían sus hornos, y sus viviendas, en las colaciones, barrios y calles de los arrabales extramuros, en la periferia de la ciudad preindustrial -véase CUADRO IV-. Descuella, en primer lugar, San Pedro de la Fuente y San Martín, con el $36.7 \%$-en este espacio urbano se ubicaba el $40 \%$ de las tiendas visitadas por el Concejo-. En segunda instancia, Viejarrúa, San Román y la calle Tenebregosa o Alta, con un 26.8 \%. La tercera zona en importancia por la acumulación de panaderos y horneros era el arrabal de Vega, en especial en las calles La Calera, San Cosme y Santa Dorotea, con el $17.1 \%$, seguidas a bastante distancia por San Juan y la Plaza de San Juan, con un $7.3 \%$, los compases del Hospital del Rey y el Real Monasterio de Las Huelgas, ambos con otro $7.3 \%$ conjuntamente, y San Esteban y Cortes, con un $2.4 \%$, respectivamente. Barrios y calles, por tanto, preñadas de hogares humildes, lejanos de las mansiones aristocráticas, de la Catedral y del Ayuntamiento. Las casas de los burgaleses se surtían, desde las afueras hacia los adentros, de pan fabricado con una harina extraída de los cereales generados en los campos que rodeaban la ciudad y molturados, amasados y cocidos por hogares que luchaban «empanizadamente "para salir adelante y mantener a sus familias con el crepitar de las llamas de sus hornos. Como el volumen de pan que fabricaban era deficitario, una buena parte de él procedía, a su vez, de los pueblos -Arcos de la Llana, Villagonzalo de Pedernales, Villariezo y Sarracín- sitos en el cuadrante sur-oeste, a varios kilómetros de distancia de la ciudad, en virtud de «la obligación que ttienen hecha de la Conducción, rremesa y abasto de pan Cozido en la Panadería de estta Ciudad y diariamentte como deven para que no faltte el surtido necesario a sus vecinos y moradores» ${ }^{57}$.

Un aspecto problemático es la diferencia que se detecta entre quienes estaban controlados por el Concejo a través de las "Visitas de tiendas» ${ }^{58}$ y quienes ejercían el panadeo de una manera "clandestina». El $75.6 \%$ de los panaderos y horneros no eran tenidos por tales por los gestores municipales o escapaban a su control -véase CUADRO V-. Era especialmente sintomático entre los panaderos, entre quienes el $86.2 \%$ eludían la mirada del Ayuntamiento - para los horneros nos topamos con un 50/50, en extrema igualdad- ${ }^{59}$. Estas diferencias, que también se detectan entre, por ejemplo, posaderas y mesoneros ${ }^{60}$, llaman la atención sobre la escandalosa problemática de la

57 AMB. Histórica. C 83-16 (1749).

58 SANZ de la HIGUERA, Francisco, "De tiendas por Burgos, ...», en Investigaciones Históricas, 26, Valladolid, 2006, pp. 163-186.

59 De los 29 panaderos fueron únicamente visitados 4, es decir, el $13.8 \%$. De los 12 horneros sólo disponían de tienda abierta, y por tanto controlados por el Concejo, la mitad.

60 En las ciudades de la época pre-industrial existían posadas secretas y mesones y tabernas clandestinos, no visitados por el Concejo y opacos desde la perspectiva fiscal. Véase SANZ de la HIGUERA, Francisco, "De tiendas por Burgos...", en Investigaciones Históricas, 26, Valladolid, 2006, pp. 164-167 (163-186). 


\begin{tabular}{|c|c|c|c|c|}
\hline CUADRO IV & \multicolumn{4}{|c|}{ Residencia de los panaderos y horneros } \\
\hline & Panaderos & Total & $\%$ & $\%$ \\
\hline San Juan & 1 & & & \\
\hline Plaza San Juan & 2 & 3 & 7.3 & 7.3 \\
\hline La Calera & 2 & & & \\
\hline San Cosme & 2 & 7 & 17.1 & 17.1 \\
\hline Santa Dorotea & 3 & & & \\
\hline Viejarrúa & 2 & & & \\
\hline San Román & 5 & 7 & 17.1 & \\
\hline Alta & 4 & 4 & 9.7 & 26.8 \\
\hline San Esteban & 1 & 1 & 2.4 & \\
\hline San Pedro de la Fuente & 14 & & & \\
\hline San Martín & 1 & 15 & 36.7 & 36.7 \\
\hline Las Huelgas & 2 & & & \\
\hline Hospital del Rey & 1 & 3 & 7.3 & 7.3 \\
\hline Cortes & 1 & & 2.4 & 2.4 \\
\hline Total & 41 & 41 & 100 & 100 \\
\hline
\end{tabular}

\begin{tabular}{|c|c|c|c|c|c|c|c|}
\hline CUADRO V & \multicolumn{7}{|c|}{ Parámetros vitales de los fabricantes de pan en Burgos (1751) } \\
\hline & & & & HOMBRES & & & \\
\hline & $\mathrm{N}^{0}$ & $\%$ & Útil/@ (1) & Útil Pan (2) & Edad (3) & Firma (4) & M2Hogar (5) \\
\hline Con tienda & 10 & 31.2 & 963 & 1002 & 38 & 25 & 133.6 \\
\hline \multirow[t]{3}{*}{ Sin tienda } & 22 & 68.7 & 1000 & 703 & 41 & 17.2 & 154.1 \\
\hline & & & & MUJERES & & & \\
\hline & $\mathrm{N}^{\circ}$ & $\%$ & Útil/@ (1) & Útil Pan (2) & Edad (3) & Firma (4) & M2Hogar (5) \\
\hline Con tienda & 2 & 22.2 & 560 & 725 & 48 & 0 & 296.3 \\
\hline \multirow[t]{3}{*}{ Sin tienda } & 7 & 77.8 & 383 & 407 & 45.5 & 0 & 110.3 \\
\hline & & & & TOTAL & & & \\
\hline & $\mathrm{N}^{0}$ & $\%$ & Útil/@ (1) & Útil Pan (2) & Edad (3) & Firma (4) & M2Hogar (5) \\
\hline Con tienda & 12 & 29.3 & 896 & 956 & 39.5 & 25 & 160.8 \\
\hline Sin tienda & 29 & 70.7 & 851 & 632 & 42 & 17.2 & 143.5 \\
\hline \multicolumn{8}{|c|}{ (1) Alcance anual del hogar: Ingresos brutos menos gastos habituales. En reales. } \\
\hline \multicolumn{8}{|c|}{ (2) Alcance anual gestado en los hornos. En reales de vellón. } \\
\hline (3) Edad media. & & & & & & & \\
\hline \multicolumn{8}{|c|}{ (4) Porcentaje de titulares del hogar que rubricaron el memorial catastral. } \\
\hline (5) Metros cuadr & dos & or ho & gar (promec & dio). & & & \\
\hline
\end{tabular}


logística urbana de los bienes de consumo en la Edad Moderna. Los panaderos y horneros con tienda legal, visitada por el Concejo, y quienes fabricaban pan y lo vendían de manera encubierta no diferían substancialmente en sus parámetros económicos y humanos y disponían, en la práctica, de unos ingresos, edades, acceso a la alfabetización y dimensiones de las viviendas más o menos similares.

Si únicamente se contara con los panaderos que aparecen censados en las visitas de tiendas -véase GRÁFICO I- sería prácticamente imposible alimentar las mesas de los burgaleses y asegurar el acceso al pan para sus hogares. Es evidente, que las ciudades disponían de un abastecimiento que escapaba al control de las autoridades, o que eran permitidos por éstas en circunstancias más o menos clandestinas o «secretas». Eso atenuaba, en la medida de lo posible, la «economía moral de la multitud $»^{61}$ y aseguraba la paz social, a pesar de todos los pesares. En los momentos de mayor inquietud, crisis económica o desabastecimiento e inflación de los precios, se desataban todos los malestares y el clamor y la violencia hacían su aparición de forma abrupta y peligrosa. Los estómagos vacíos llenaban las bocas de palabras agrias y las manos de violencia.

Los panaderos y horneros de la ciudad de Burgos vivían en una precariedad difícil y su producción no aseguraba, en efecto, el suministro a la totalidad de sus vecinos y habitantes. Una proyección hipotética del número de fanegas cocidas por semana, en función de los propios cálculos que los panaderos y horneros significaron en sus memoriales -véase CUADRO VI-, nos indica que de sus hornos salía el $28.6 \%$ de los panes que precisaba la ciudad. Me explico. Los panaderos y horneros burgaleses manejaban a la semana 408 fanegas de cereales panificables, en especial trigo blanquillo y trigo alaga. De cada fanega salían de promedio 26 panes, es decir, 10.808 panes/semana, que multiplicados por 54 semanas suponían 572.832 panes/ año ${ }^{62}$. Ya sabemos qué cantidad de pan se obtenía en los hornos de la ciudad.

¿Y la demanda? A través del documento "Regulación del Pan que Lexitimamente se necesita para el diario Alimento de los Vecinos», de aproximadamente $1764^{63}$, se extrae que en las colaciones de San Juan, San Gil, San Esteban y Santamaría se consumían

${ }_{61}$ THOMPSON , Edward P., «La economía «moral» de la multitud en la Inglaterra del siglo XVIII», en Past \& Present, 50, Londres, 1971, pp. 76-136.

62 Este cómputo deviene de una proyección aproximativa del número de fanegas de trigo cocidas por los panaderos y horneros de Burgos en 1751 -véase CUADRO VI- y al promedio de panes gestados por fanega en Arcos de la Llana en 1749. En función de las declaraciones catastrales de los propios panaderos y horneros -enfatizados en negrita-, he proyectado una reconstrucción hipotética de las Fanegas Cocidas por Semana con el siguiente patrón: 300 reales, 2 a 4 FPC; 500600 reales, 6 a 8 FPC; 800 reales, 10 FPC; 1100 reales, 14 FPC; 1200 reales, 16 FPC; 1500 reales, 24 FPC y 2000 reales 32 PFC.

63 AMB. Histórica, C 1-7-28 (1764). 


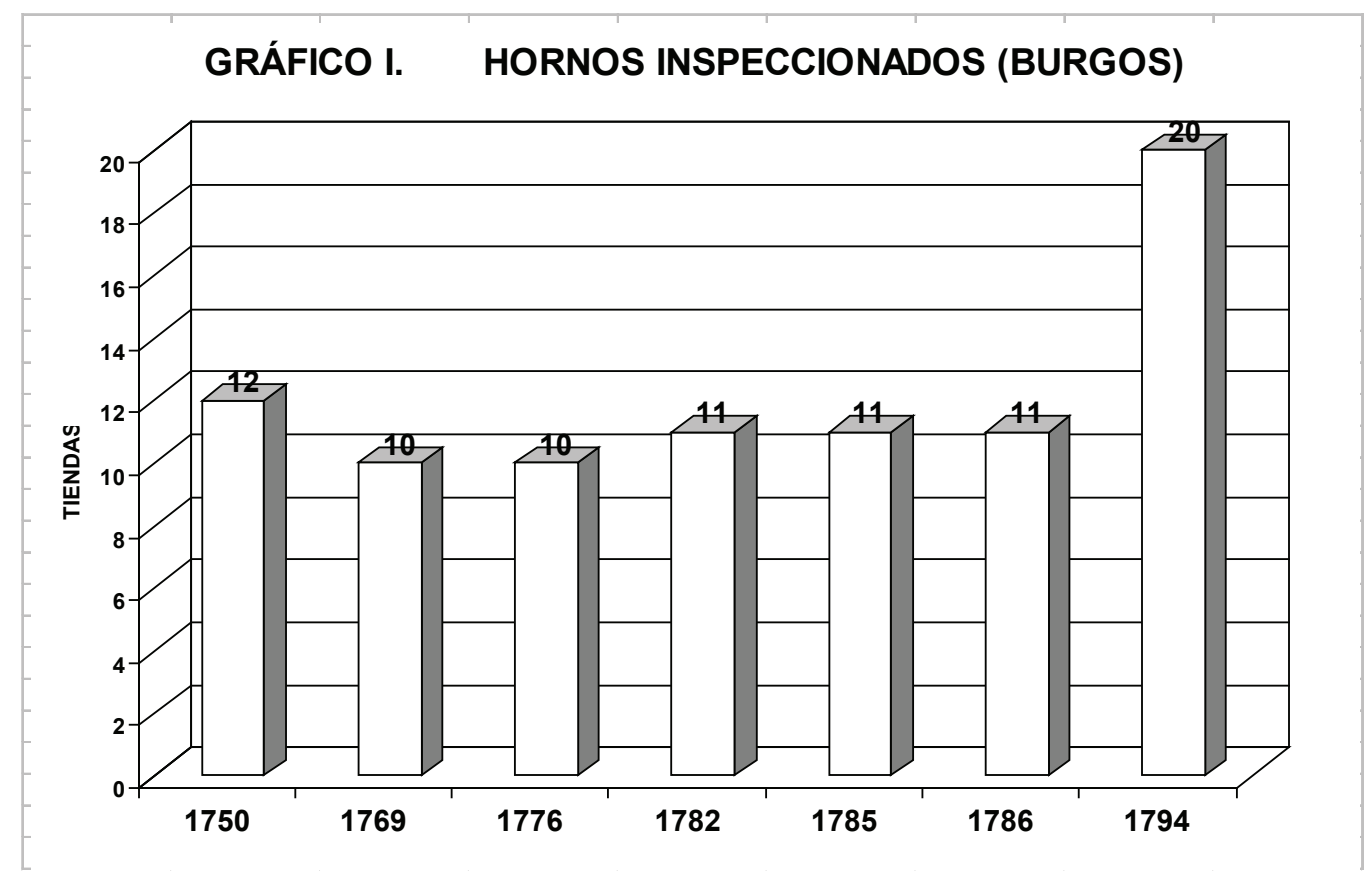

diariamente 4.022 panes -a medio pan por persona, de promedio-, es decir, 1.468.030 panes/año -véase CUADRO VII-. Aplicado a las colaciones no regladas en el citado documento municipal el prorrateo medio pan/persona, hemos de añadir al consumo panificado burgalés otros 1.469 panes/día, es decir, 536.185 panes/año. Sumadas ambas partidas, los hogares de Burgos darían cuenta al año de, más o menos, 2.004.215 panes, lo cual significa, en números redondos, que era preciso traer de fuera del recinto de la ciudad 1.431.383 panes al año. ¿¿ónde encontrarlos?

Tradicionalmente, Arcos de la Llana y algunas localidades cercanas habían sido los vectores logísticos esenciales. A partir de 1749, una «Escriptura de obligación y Convenio enttre esta villa de Arcos y la Ciudad de Burgos [que también se suscribió con Villagonzalo de Pedernales, Villariezo y Sarracín] sobre el abasto de 375 fans de trigo que se obliga la Villa a dar en pan cocido a dha Ciudad en Cada Semana, otorgada en fuerza de Real decretto de Su Magd $\rangle^{64}$, une inexorablemente a los panaderos de dichos pueblos con las mesas de los vecinos urbanos. Arcos de la Llana enviaba a Burgos 9.750 panes/semana, es decir, 526.500 panes/ańo, o sea, un $26.3 \%$ del pan deglutido en la ciudad ${ }^{65}$. Los vecinos de Sarracín se encargaban del panadeo de 150 fanegas de trigo por semana, es decir de la

\footnotetext{
64 AMB. Histórica, C 83-16 (1749).

65 Las 375 fanegas de trigo suponen, a un promedio de 26 panes/fanegas, 9.750 panes/semana.
} 


\begin{tabular}{|c|c|c|c|c|}
\hline CUADRO VI & \multicolumn{4}{|c|}{ Profesionales de la fabricación del pan en Burgos (1751) } \\
\hline Panadero/Hornero & Ubicación & Útil/@ Pan (1) & FPC (2) & Quehacer \\
\hline Francisco Asenjo & San Juan & 1200 & 16 & Panadero \\
\hline Ana Pérez & Plaza San Juan & 350 & 4 & Panadera \\
\hline José Asenjo & Plaza San Juan & 1100 & 14 & Panadero \\
\hline María Herbías & La Calera & 1100 & 14 & Panadera \\
\hline Miguel Mayor & La Calera & 700 & 8 & Hornera \\
\hline Matías Maeso & San Cosme & 330 & 2 & Panadero \\
\hline Pedro Viguer & San Cosme & 1100 & 14 & Panadero \\
\hline Marcos González & Santa Dorotea & 190 & 2 & Hornero \\
\hline Leonardo Llanos & Santa Dorotea & 550 & 8 & Panadero \\
\hline José Lozano & Santa Dorotea & 1220 & 16 & Hornero \\
\hline Matías Delgado & San Román & 1500 & 24 & Panadero \\
\hline Martín Díez & San Román & 500 & 8 & Panadero \\
\hline Juan Pesquera & San Román & 1400 & 24 & Panadero \\
\hline Francisco Fernández & San Román & 500 & 8 & Panadero \\
\hline Blas Rangel & San Román & 1200 & 16 & Panadero \\
\hline Vicente Pardo & Viejarrúa & 800 & 10 & Panadero \\
\hline Teresa Pérez & Viejarrúa & 500 & 8 & Panadera \\
\hline Andrés Arribas & Alta/Tenebregosa & 800 & 10 & Panadero \\
\hline José García & Alta/Tenebregosa & 1100 & 14 & Panadero \\
\hline Francisco Saiz Extremiana & Alta/Tenebregosa & 1600 & 24 & Hornero \\
\hline $\mathrm{M}^{\mathrm{a}}$ José Ibeas & Alta/Tenebregosa & 200 & 2 & Panadera \\
\hline Manuela Arnaiz & San Pedro de la Fuente & 600 & 6 & Panadera \\
\hline Ángela González & San Pedro de la Fuente & 500 & 8 & Panadera \\
\hline Manuel Moreno Valencia & San Pedro de la Fuente & 500 & 8 & Panadero \\
\hline Agustín Sáez & San Pedro de la Fuente & 300 & 2 & Hornero \\
\hline Manuel Arce & San Pedro de la Fuente & 600 & 6 & Panadero \\
\hline Manuel Garzón & San Pedro de la Fuente & 600 & 8 & Panadero \\
\hline Francisca Miguel & San Pedro de la Fuente & 600 & 8 & Panadera \\
\hline Pedro Miñón & San Pedro de la Fuente & 600 & 8 & Panadero \\
\hline Antonio Ruiz & San Pedro de la Fuente & 300 & 4 & Panadero \\
\hline Domingo Pardo & San Pedro de la Fuente & 200 & 2 & Panadero \\
\hline Antonio Barriocanal & San Pedro de la Fuente & 500 & 8 & Hornero \\
\hline Manuel Páramo & San Pedro de la Fuente & 2000 & 32 & Hornero \\
\hline José Rodrigo & San Pedro de la Fuente & 300 & 4 & Hornero \\
\hline Ángela Martínez & San Pedro de la Fuente & 150 & 2 & Hornera \\
\hline $\mathrm{M}^{\mathrm{a}}$ Arnaiz & San Martín & 300 & 4 & Panadera \\
\hline Manuel Sevilla & San Esteban & 1100 & 4 & Panadero \\
\hline Juan Ruiz & Las Huelgas & 500 & 8 & Panadero \\
\hline Juan Martínez & Las Huelgas & 1000 & 14 & Panadero \\
\hline Manuel de la Fuente & Hospital del Rey & 1000 & 14 & Hornero \\
\hline Tomás Iglesias & Cortes & 200 & 2 & Hornero \\
\hline
\end{tabular}

fabricación de 210.600 panes/año ${ }^{66}$-el $10.5 \%$ del pan consumido en la ciudad-. El restante $34.6 \%$ procedía de Villagonzalo de Pedernales (13.4\%) y de Villariezo (21.2

66 Sabemos de las obligación de los panaderos de Sarracín, enviar 150 fanegas de pan cocido a la semana, por AMB, Histórica, HI-4914 (1755-1756), folio 7. 


\begin{tabular}{|c|c|c|}
\hline CUADRO VII & \multicolumn{2}{|c|}{ Consumo de pan en Burgos } \\
\hline & Panes/día & Hogares \\
\hline San Juan & 1606 & 2454 \\
\hline San Gil & 563 & 932 \\
\hline San Esteban & 432 & 706 \\
\hline Santa María & 1421 & 2699 \\
\hline San Pedro de la Fuente & 293 & 586 \\
\hline Cortes & 100 & 201 \\
\hline Villimar & 123 & 247 \\
\hline Villatoro & 126 & 252 \\
\hline Villagonzalo de Arenas & 32 & 65 \\
\hline Hospital del Rey & 125 & 250 \\
\hline Las Huelgas & 130 & 260 \\
\hline Alta/Tenebregosa & 227 & 454 \\
\hline Santa Águeda & 313 & 626 \\
\hline
\end{tabular}

$\%)^{67}$. En los cálculos de volumen de panificación, cada panadero vendría a producir, de promedio, 4 fanegas de trigo a la semana, como se desprende de algunos memoriales catastrales ${ }^{68}$.

La rúbrica de dicha escritura pretendía reparar las constantes problemáticas que las panaderas de Arcos de la Llana y las localidades citadas generaban a la ciudad. Por si quedaba alguna duda, «El Rey [merced a un Real Decreto] ha resuelto que para que esa Ciudad, Su Común y la Tropa que esttá alojada en ella no padezcan la escasez de pan Cozido a justos y moderados prezios que es rezelable se obliguen los panaderos de la Villa de Arcos a la Correspondientte porzión diaria que a ejemplo de ottros pueblos de Igual ttratto y Granjería aseguren ttan yndispensable yÚttil providencia...» ${ }^{69}$.

En julio de 1753, el marqués de Espinardo, intendente y corregidor de Burgos y su Provincia, hacía llegar a las autoridades de Arcos, Villagonzalo, Sarracín y Villariezo

67 He efectuado una proyección -una reconstrucción hipotética- del número de fanegas de pan cocido pergeńadas por los vecinos de Villagonzalo de Pedernales (38) y Villariezo (58), a razón de 4 FPC por vecino/semana, tal y como ellos mismos indicaron en sus memoriales catastrales.

68 Descuellan, en especial, las palabras de Blas de Porres, quien redactó su propio memorial, porque sabía escribir. Además del «ministerio de la labranza», indicó que actuaba como "Panadero obligado en llevar Pan a Burgos y Por ser Poco el Caudal de Panadería me dejará al año Zinquenta Rs, digo que quezo Por semana quatro $f$ s, dos al martes y dos al Sábado». ADPB. CE. RP. Villariezo. Libro 2418, folio 19. Véase también Sebastián de Santa Cruz - "Panadero que quezo quatro fs a la Semana" (folios 327-329), Pedro Casado - «... a dho trato quezo Cada Semana quatro fs de trigo que azen al año quatro rentas Con las quales Manttengo mi familia» (folio 318), José García - «... Panadero para llevarlo a la Ziudad de Burgos, quezo Cada Semana tres fs» (folios 218-227), Francisco Gómez, menor, - «... trato de la Panadería y quezo quatro fs de trigo Cada Semana Con la qual Manttengo La familia» (folios 164-166) y Francisco Pérez Espiga - «... en el ofizio de la panadería quezo quatro fs de trigo Cada Semana» (folio 161).

69 AMB. Histórica, C 83-16 (1749, sin foliar. 
que era notorio que "por sus Vezinos no se Cumple con la obligación que ttienen hecha de la Conducción, rremesa y abasto de pan Cozido en la Panadería de estta Ciudad y diariamente como deven para que no faltte el surtido nezesario a sus vecinos y moradores como se Experimenta y con estte mottibo se da lugar a clamores y benderlo a excesivo prezio, contraviniendo a la obligación hecha» ${ }^{70}$. Las cargas que los pueblos abastecedores y sus vecinos sufrían cortocircuitaban la logística habitual del pan.

De una manera ejecutiva, se dan las órdenes oportunas para que, en cada una de las localidades citadas, se "practtique reconocimiento de todas las Casas y el pan que hallen lo hagan asimismo ttraer sin pérdida de tiempo a esta Ciudad y los aperciban a dhos Sus Vecinos no falten al Cumplimiento de su obligazión ni essttrabien ni bendan dho pan a ottras parttes, como lo hazen», pena de 200 ducados $^{71}$. En Villagonzalo, sorprendidos sus vecinos panaderos «a cosa de las doze de la Noche» del 14 de julio de 1753, hallaron 260 panes, en Arcos, 140 fanegas de pan cocido, en Villariezo 58 y en Sarracín $11^{72}$, atrapados en similar forma, con nocturnidad y alevosía. El miedo de las autoridades venía motivado por «tener a estta Ciudad sin el Pan diario a que están obligados, exponiéndose por ello y su crecida falta estos vecinos a un tumultto del que se pueden originar gravisimos daños, dignos del más puntual y eficaz remedio, $y$ respecto de haverse carezido estos días de este tan preciso e indispensable alimento, mayormente practicado el despacho del Pan diferentes Panaderas (...) sin concurrir por ello a la Panadería para que están destinadas, siendo como es esto un medio tan clandestino y ageno a toda equidad y Justicia, digno del más severo y exemplar Castigo» ${ }^{73}$. Las panaderas de las localidades afectadas venían quejándose desde hacía mucho tiempo de problema graves en el suministro de "Leña y hornija para cozer Pan y conducirlo para el consumo de estta Ciudad de Burgos», de la adversa climatología -tanto por "la mucha escasez de Aguas que se a experimentado» como por los «Grandes Yelos»

70 AMB. Histórica. C 12-b-2 (1753-1754). Papeles varios sobre abasto de pan a esta Ciudad. Dicha problemática recorre, de manera insistente, la totalidad del siglo. Ejemplos de ello en AMB. Actas de Gobierno, Regimiento del 22 de junio de 1737, folios 153-155 o AMB. Histórica, C 55/13 (17 de agosto de 1763), "Mediante no conducir los Vecinos de la villa de Arcos diariamente el pan cozido necesario para el Abasto desta Ciudad». Desde "ynmemorial tiempo», y más desde la escritura de 1749, los vecinos de Arcos de la Llana surtían de pan cocido a Burgos. La interrupción del panadero generaba que «Su Común [sufriera] Conocida falta en grave perjuizio de la Causa pública $y$ de los viandantes, de quienes se está oyendo cada día repettidas quejas».

71 AMB. Histórica. C 12-b-2 (1753-1754). Las amenazas de las autoridades contra los vecinos obligados a cocer pan, sobre todo en lo tocante a ubicar «a su Costa dos Soldados» para vigilar el panadero y penas de cárcel para quienes obstaculizaran, impidieran o sabotearan el suministro de pan, aterrorizaban a aquellos humildes campesinos y panaderos, que difícilmente alcanzaban alguna ganancia anual si la climatología, los precios de los cereales y de la madera para cocer u otros imponderables dinamitaban sus quehaceres productivos. El pan barato y sostenido para la ciudad era gravoso e insostenibles para sus precarias y rústicas economías.

72 AMB. Histórica, C 12-b-2 (1753-1754), folios 3-6. En el documento se significan las fanegas de pan cocido y de harina halladas en las casas de los vecinos, uno a uno.

73 AMB. Historica, C 12-b-2 (1753-1754), folio 8. 
que impedían el tránsito normal y la molturación en los molinos-, de los elevados precios de los cereales y de los problemas de ajustes de precios del pan en la ciuda$\mathrm{d}, \ldots{ }^{74}$. En esencia, los vecinos de los pueblos panaderos retrasaban o entorpecían los envíos, ocultaban sus existencias para especular con los precios, cometían fraudes en los transportes, circunstancias que generaban desabastecimientos traumáticos y los correspondientes «clamores» entre el público urbano.

En este sentido, nos hallamos ante un cúmulo de problemáticas que, a la postre, son un modelo universal de análisis que se repite, inexorablemente, en las ciudades del Antiguo Régimen. Así, por ejemplo, «Madrid fue incapaz de conseguir una industria autosuficiente y necesitó el apoyo de una red de molturación y panificación muy alejada de sus límites jurisdiccionales ${ }^{75}$, con las consiguientes dependencias del exterior, quejas de panaderos y consumidores, desabastecimientos traumáticos, etcétera.

En este contexto se produjo la búsqueda de soluciones por parte de los diferentes actores burgaleses. $\mathrm{Y}$ en este caldo de cultivo el Cabildo Catedral, bastante sensibilizado contra el Concejo, y contra las autoridades borbónicas, por ésta y otras problemáticas de consumo ${ }^{76}$, decidió embarcarse en la fabricación de su propio pan.

\section{EL SUMINISTRO EXCLUSIVO DE PAN PARA EL CABILDO CATEDRAL}

Si el pan que llegaba a las panaderías de Burgos estaba sometido a graves tensiones, en especial en lo tocante a la sostenibilidad y la fluidez en el suministro y a la calidad y coste del mismo, los prebendados de la Catedral no podían permanecer al margen, en la molicie de la inacción y la irresponsabilidad del victimismo cómplice. Es por ello que, como se ha señalado al principio de estas páginas, a finales de febrero de 1754, el Capiscol Zamora Huidobro plantea en el Cabildo independizarse del abasto público y crear

74 AMB. Histórica, HI-4914 (1755-1757). Sobre la congelación de los dedos y del suministro panadero, sobre climatología en el XVIII, véase, entre otras muchas, las abundantes obras y excelente producción científica, ALBEROLA ROMÁ, A., «»No puedo sujetar la pluma de puro frío, porque son extremados los yelos»: el clima en la España de los reinados de Felipe V y Fernando VI a través de la correspondencia de algunos ilustrados», en Investigaciones Geográficas, 49, Alicante, 2009, pp. 65-88 y, sobre todo, su prodigiosa y proverbial Quam la pluja no sap ploure. Sequeres $i$ riuades al Pais Valencia en l'edat moderna, Valencia, Universidad de Valencia, 2010.

75 BERNARDOS SANZ, José Ubaldo, No sólo de pan..., Madrid, Tesis doctoral inédita, pp. 212. Véase también CORTÉS PEÑA, Antonio Luis, "Una petición de los panaderos...», pp. 261-265.

76 El Cabildo Catedral mantuvo con grave contencioso con el Concejo a cuenta de la logística del cacao. Véase SANZ de la HIGUERA, Francisco, "Clero catedralicio y consumo de chocolate en el Burgos del Setecientos», en Tiempos Modernos, Logroño (en proceso de evaluación por el Consejo de Redacción). A través de las Actas Capitulares accedemos a las entregas de vino, aceite y carneros a los prebendados. ACCB. AC. LR 108. Cabildo del 18 de Julio de 1763, folio 438. 
los «Ynstrumentos necesarios», una casa-horno propia, «logrando por estte medio prohehería [a] todos los Yndibiduos deel Cavildo de Pan de mejor Calidad y más varato» ${ }^{77}$. No tardaron mucho los capitulares en enderezar la cuestión. El 26 de abril de 1754, el Capiscol y el canónigo Quintana pusieron en conocimiento de sus «compadres» capitulares la existencia de un pliego de "Condiciones con que los Panaderos se obligan a dar pan a V. S. y sus individuos ${ }^{78}$.

Las «Condiciones con que se obligan Varios Panaderos a surtir de Pan a los Yndividuos de estta Santta Yglesia y a sus Dependientes, como también al Palazio del Illmo Señor Arzobispo, Hospital de San Julián, Seminario y Mozos del Coro, dando por cada fanega de pan blanquillo a razón de 24 Panes, los 18 en panes de a dos Libras y media y los restantes en Panecillos de a tres o quattro en Cuartal, y deel trigo alaga a razón de 27 Panes por fanega, los 21 en Cuartales y los restantes en Panecillos $»^{79}$, estaban encaminadas a la consecución del dicho objetivo, irrenunciable, dar pan de calidad y barato al Cabildo, y para ello se plantearon dinamizar sus propios inmuebles y canalizar hacia la casa-horno su trigo. El proyecto de abasto de pan contenía, en esencia, varios aspectos fundamentales, tendentes a ubicar el dónde fabricar el pan, con qué trigo elaborarlo, cuándo surtir de pan a los prebendados, con qué aperos elaborarlo y cómo conseguir que fuera de calidad y de buen gusto.

Un primer aspecto básico era, en efecto, dónde ubicar los hornos. En principio, se consideró, en el apartado primero de las «Condiciones», "Que los hornos, Casa y demás Oficinas se han de hazer frente deel Hospital de San Julian en la Conformidad que dhos Panaderos proyectaren ${ }^{80}$. Esta inicial, y pretendida, ubicación fue cuestionada en mayo de 1754 cuando se comenzó a barajar, en el seno del Cabildo, si era más idóneo «para la disposición y probidenzia de Ornos y Oficinas para hazer el Pan (...) en el sittio de Barrantes [Hospital de San Julián] en las Casas que están una frentte del Hospital y ottra en el Labadero, con menos gastos y dispendio que ejercutarlas en ottra parte» o sería más conveniente, "teniendo presentte la mentte del Cavildo y algunos reparos que se ofrecieron, vaian probidenziando y proiecttando sobre su construcción [en otro sitio] en la inttelijenzia de que no se fabrique Pozo ni fuente en aquel Sittio para evitar por estte medio qualquiera rezelo que se puede ofrecen. El temor a los incendios ${ }^{81} \mathrm{y}$ a las quejas de los vecinos gravitaba poderosamente sobre ésta y otras decisiones. Quedaba, por tanto, abierta la puerta a que aquellos prebendados «que ttengan algún conozimiento escriban a dónde les parezca» debían

\footnotetext{
77 ACCB. AC. LR 106, Cabildo del 28 de febrero de 1754, folio 686.

78 ACCB. AC. LR 106, Cabildo del 26 de abril de 1754, folio 712.

79 ACCB. AC. LR 106, Cabildo del 26 de abril de 1754, folio 712.

80 ACCB. AC. LR 106, Cabildo del 26 de abril de 1754, folio 712.

81 Véase SANZ de la HIGUERA, Francisco, "Una ardiente operación urbanística y crediticia. El incendio de las casas de la calle La Calera y el Cabildo Catedral de Burgos (1773-1776)», en Cuadernos de Estudios del Siglo XVIII, Oviedo (en fase de evaluación por el Consejo de Redacción)”.
} 
instalarse los hornos, aspecto que se complementa con la necesidad de «saber si avrá algunos Panaderos de sattisfazción que puedan venirn y en qué condiciones ${ }^{82}$. En el proyecto de escritura para dar abasto de pan al Cabildo presentada por Fernando Zernuda, con fecha de 12 de julio de 1754, se resolvía esta problemática de la ubicación en la condición séptima. En ella se afirmaba taxativamente "Que porparte deel Cavildo se han de poner las oficinas correspondientes al ministerio en las tres Casas propias deel Cavildo a la Callejuela de la Merced, dándolas al Corral correspondiente y en la forma que deja dho Fernando proyectado». Una cuestión espinosa añadida era la de quién debía sufragar su usufructo. En principio, se sugirió que «todos los gastos de [las] dos Casas ha de satisfacer dho Fernando en cada un año, dejando el alto de la última, que es la deel Jardin, libre», aunque, finalmente, se estipuló que serían 100 reales/año ${ }^{83}$.

Y en efecto, y tal como se desprende del «Libro de Cabezas de Casas» de la Mesa Capitular ${ }^{84}$ y de los Libros de Redondo de cada año ${ }^{85}$, la casa número 195 de entre los inmuebles urbanos propiedad del Cabildo Catedral, sita en la calle La Calera, cambió de ocupantes. Desde junio de 1749, estaba arrendada a María de Herbías, viuda, analfabeta, de edad avanzada, "Panadera del Pan que se da a los Pobres del Sepulcro»" ${ }^{86}$, quien alquiló, en primera instancia, por tres años (1749-1752) ${ }^{87}$, y, en segundo término, por otros tres (1752-1754) ${ }^{88}$ a razón de 325 reales y 10 gallinas al año. Al ser designada dicha casa por el Cabildo como lugar para la ubicación de su panadería, "corrió con dha casa [María de Herbías] hasta fin de diciembre de 1754 en que salió de ella para que entrase el Hornero de Su Señoría el Cavildo. En esta casa se hicieron los Hornos para cocer el pan para Su Señoría el Cavildo, por lo que, y [para] evitar la Vivienda de ella, Dn Jazinto Pérez Herreros, Capellán deel Númo deesta Sancta Yglesia, a cuio Cargo corre la Admón de dhos Hornos y pan por nombramiento de dhos Señores, no se ha de cargar rentta alguna por dha Casa $^{89}$. Posteriormente, a partir de febrero de 1759, la llevaron en renta Miguel de Rivero y Bartolomé Turio, panaderos, «en precio cada mes de 25 reales Vellón con la obligación de hazer la paga adelantada en cada uno, en lugar de fianza con las Condiciones deel Cavildo» ${ }^{90}$. Esta fórmula no duró mucho, dado que en junio del dicho año, 1759,

82 Las citas textuales de este párrafo en ACCB. AC. LR 106, Cabildo del 6 de mayo de 1754, folio 716.

83 ACCB. AC. LR 106, Cabildo del 12 de julio de 1754, folio 742 y AHPB. PN. Juan Antonio Fernández Guilarte. Legajo 7019 (13 de agosto de 1754), folio 372.

84 ACCB. Libros de Subsidio y Excusado y otros. Libro 90. Libro de Cabezas de casas (1710-1789), Casa no 195 (La Calera), folio 225.

85 ACCB. Libros de Redondo (1700-1799).

86 ADPB. CE. RP. Libro 346, folio 83.

87 Escriturado por Juan Antonio Fernández Guilarte en 24 de abril de 1749.

88 En la escribanía del Cabildo, por Juan Antonio Fernández Guilarte (9 enero de 1752).

89 ACCB. Libro de Cabezas de casas, Casa no 195 (La Calera), folio 225.

90 ACCB. Libro de Cabezas de casas, Casa no 195 (La Calera), folio 225. 
Manuel de Noriega, como principal, y don Pedro Celestino Tomé Carrera, arcediano de Burgos ${ }^{91}$ como fiador, se hicieron con el alquiler del inmueble por tres años y 370 reales más 10 gallinas al ańo ${ }^{92}$, que posteriormente, a partir de 1762, se verían incrementados hasta 470 reales y 10 gallinas/ańo, aunque con un contrato de nueve ańos ${ }^{93}$. El coste de las obras en la casa-horno se evaluaron en 2 ó 3.000 reales, lo que significaba superar la escasa infraestructura que tenía prevista María de Herbías y «hazer los Ornos en La Calera, precaviendo (...) qualquier daño que en algún Caso irregular se pudiera seguir a las Casas inmediatas» ${ }^{94}$. Un aspecto muy importante de la nueva infraestructura era que «los Hornos se han de calezar (sic) con materia que no pueda dar mal gusto al pan» ${ }^{95}$.

Otro de los asuntos fundamentales consistía en posibilitar un acceso sostenido a la harina por parte de los panaderos para lo cual era imprescindible una fluida disponibilidad de moliendas. Es ese sentido, el Cabildo puso al alcance de Zernuda «el Molino de dos ruedas que tiene en el Morco, poniendo Unas Ruedas de Toba para el trigo blanquillo y las otras para la alaga», si bien el molino, como las demás oficinas y casas habían de pagar su correspondiente alquiler ${ }^{96}$. También le hizo llegar "dos Cedazos que ai en el Combentto de Carmelitas de esta Ciudad y un Arnero para abañar como lo ai en el desierto si fuere dable el conseguirle, los quales han de volver a entregar tales y $\tan$ buenosn $^{97}$.

¿Y qué se llevaría al molino y después a los hornos panaderos? Cada mes se habría de entregar la cantidad de trigo necesaria, dando razón puntual de lo gastado, y para ello "por parte deel Cavildo se ha de hazer a su tiempo la Compra de trigo blanquillo con intervención deel Panadero para la Satisfacción de la Calidad y si el Panadero se quisiere Valer de alguna Cantidad de dho trigo se ha de dar por el Cavildo a coste y portter ${ }^{98}$. El proceso, por tanto, tenía varias fases, que articulan en un flujo que iba desde el antes al después de fabricar el pan. El Cabildo estaba en la obligación de "hazer prevención de trigo en tiempos oportunos» y siempre con la colaboración directa de Fernando Zernuda "para la elección de la mejor Calidad». El Diputado del Cabildo que fuese a efectuar las compras de grano estaba prevenido de las cantidades de trigo preciso. Por cada fanega recibida de

91 SANZ de la HIGUERA, Francisco, "Carrera eclesiástica y algunos deslices de Felipe del Hoyo y Pedro Celestino Tomé, arcedianos de Burgos (1731-1784)», en Hispania Sacra, 124, Madrid, 2009, pp. 649-690.

92 Escriturado por Juan Antonio Fernández Guilarte, notario del Cabildo, el 23 de mayo de 1759. ACCB. Libro de Cabezas de casas, Casa no 195 (La Calera), folio 225.

93 En la escribanía del Cabildo, el 9 de marzo de 1762 por Juan Antonio Fernández Guilarte.

94 En efecto, los temores se materializaron en un pavoroso incendio desatado en las inmediaciones de la casa no 195 que devoró las casas 190, 191, 192 y 193 de la citada calle La Calera en la noche del 23 de agosto de 1773 .

95 ACCB. AC. LR 106, Cabildo del 26 de abril de 1754, folio 712 (Condición 7a).

96 ACCB. AC. LR 106, Cabildo del 26 de abril de 1754, folio 712 (Condición 2a).

97 ACCB. AC. LR 106, Cabildo del 26 de abril de 1754, folio 712 (Condición 6a).

98 ACCB. AC. LR 106, Cabildo del 12 de julio de 1754, folio 742 (Condición 1a). 
trigo, el panadero había de dar 26 panes de peso de $2 \frac{1}{2} 2$ libras; los 21 de flor o primera suerte, dividido cada "Quarttal» en 3 ó 4 panecillos "de igual peso que lo de Arcos», y los 5 restantes de segunda suerte en medios cuartales. La distribución del pan blanquillo se efectuaría tres veces cada semana y la de alaga solamente dos, siendo responsabilidad de los prebendados acudir a por su suerte. Los panes cocidos se entregarían la tarde o la noche antecedente, y a por ellos acudirían al horno los criados o criadas de los capitulares con la «Tarja» o señal que determinase el Cavildo. Los prebendados que prefirieran dar trigo de sus trojes, de sus prebendas particulares, habrían de participarlo al Cabildo y al panadero ocho días antes, para que, "con la noticia individual de todo», se tomara las providencias oportunas a la hora de realizar las compras ${ }^{99}$.

En febrero de 1755, se perfiló otro de los asuntos urgentes. ¿Quién haría las compras de grano y vigilaría el panadeo? Este asunto venía tratándose desde septiembre de 1754, puesto que el Cabildo habría de indicar el procedimiento para pagar las oportunas compras de trigo alaga y blanquillo, que no sería otro que «la Maiordomía franquee el Caudal necesario» ${ }^{100} \mathrm{y}$ "desttinar Persona que corra con esta incumbencia» ${ }^{101}$. Sobre la "Provisión sobre panadería y poner sujetto que corra con la Quenta en adelante», el Capiscol informó "esttar todas las cosas tocantes al proiectto de Panadería con la mayor formalidad y averse liquidado y dado las Quentas hasta fin de Diciembre [de 1754]», pero que "era preziso desttinar algún Sugetto que llebase en adelantte quentta formal de todas las menudenzias que ocurran». El Cabildo, y entre ellos Zamora Huidobro, Capiscol, estuvieron de acuerdo en que el más idóneo era un capellán del número, don Jacinto Pérez, «quien se hallaba instruido en estta materia por el Sor Quintana». Pérez viviría en la casa con el panadero, «esttando a la mira de ttodo $[\mathrm{y}]$ pudiera precaver algunos incombenienttes y Zelar el que se diese el Pan de mejor Calidad y sattisfazción» ${ }^{102}$.

Con tales parámetros, Fernando Zernuda, vecino de la villa de Zaratán, asumió "la Obligazión de dar pan de trigo blanquillo de la misma Calidad que se acostumbra dar en la Ziudad de Valladolid a los Señores Deán y Cavildo y a los Yndividuos de ella por espazio de seis años» ( $1^{\circ}$ de octubre de 1754 - final de septiembre de 1760) ${ }^{103}$. Zernuda recibiría 350 reales «para traer su Familia y lo necesario para el Cumplimiento de la Obligación» más 400 reales en caso de que el Cabildo lo despidiera antes de cumplir el contrato o que

99 ACCB. AC. LR 106, Cabildo del 12 de julio de 1754, folio 742 (Condición 2a a 5a) y ACCN. AC. LR 106, Cabildo del 23 de agosto de 1754, folio 756.

100 SANZ de la HIGUERA, Francisco, «Los mayordomos de la Mesa Capitular de la Catedral de Burgos en el Setecientos», en Trocadero, Cádiz (en proceso de evaluación por el Consejo de Redacción).

101 ACCB. AC. LR 106, Cabildo del 30 de septiembre de 1754, folio 771.

102 ACCB. AC. LR 106, Cabildo del 20 de febrero de 1755, folio 818.

103 AHPB. PN. Juan Antonio Fernández Guilarte. Legajo 7019 (13 de agosto de 1754), folio372. 
«dho fernando enferme o muera» ${ }^{104}$. Zernuda se comprometía con el Cabildo a no defraudar las expectativas creadas. Si además "hiziese otra obligazión a Comunidad o particulares de esta Ziudad para darles pan ha de ser con la Calidady Condizión de que no ha de poder admitir trigo que no sea de igualdad bondad que lo que tubiere lo de el Cavildo» ${ }^{105}$.Todo se prometía muy feliz pero el devenir de la panadería capitular comenzó pronto a sufrir problemas importantes tanto de calidad como de contabilidad.

\section{DE LA DEGUSTACIÓN AL FRACASO DE UN PROYECTO PANADERO}

El 22 de noviembre de 1756, ya era evidente que las cuentas no presentaban buen aspecto. Los Señores de Hacienda expusieron el panadero tenía contra sí 1.600 reales «y aún algo más» de alcance, es decir, de pérdidas, «sin que hayan podido reducir a ajustar quentta por ser hombre mui disidioso y que no cumple con su obligazión, por lo que muchos Sres [prebendados] se han rettraído de gastar y Consumir el Pan por no ser de Calidad». En la práctica, el Cabildo estaba ya maniobrando "con todo sigilo» para que liquidara la cuenta y «muden de mano y soliciten buscar otro Panadero de [mayor] satisfacción» ${ }^{106}$. La renovación de Zernuda pendía de un hilo. El día 26 de noviembre el Doctoral y los dichos Señores de Hacienda, después de hablar con el panadero, habían conseguido rebajar la deuda a 1.400 reales y Zernuda "dio la palabra de satisfacer poco a poco» el descubierto. Aventuraban que sería presuntamente "fázil algún recobro de prompto», pero advertían que había condescendido "por no exasperarle». El agrio carácter y las pésimas prácticas panaderas de Fernando Zernuda traían la intranquilidad a los capitulares, obligados a buscar el «medio más suave para la Cobranza» y actuar con mucha prudencia. El Cabildo les mandataba que "practtiquen todo quantto les parezca más útil y combenientte», porque el pan de los capitulares estaba en peligro $^{107}$.

El Lectoral Prieto Bustamante ${ }^{108}$ puso la puntilla cuando el 18 de abril de 1757 exigió abiertamente, y con el coraje que le caracterizaba, que «el Panadero diese mejor Pan, pues es mui malo lo que embiava, por lo que retraía a muchos Sres a tomarlo» ${ }^{109}$. No fue

\footnotetext{
104 ACCB. AC. LR 106, Cabildo del 12 de julio de 1754, folio 742 (Condición 8a).

105 ACCB. AC. LR 106, Cabildo del 12 de julio de 1754, folio 742 (Condición 10a).

106 ACCB. AC . LR. 106, Cabildo del 22 de noviembre de 1756, folio 124-125.

107 ACCB. AC. LR 106, Cabildo del 26 de noviembre de 17556, folio 131.

108 Véase SANZ de la HIGUERA, Francisco, «La librería del canónigo lectoral Prieto Bustamante: Libros y mesas de trucos a la greńa. Burgos (1749-1766)», en ÁLVAREZ SANTALÓ, León Carlos (Coord.), Estudios de historia moderna en homenaje al profesor Antonio Garcia-Baquero, Sevilla, 2009, pp. 639-660 y SANZ de la HIGUERA, Francisco, "Seminario de San Nicolás (Burgos, 1843): una rectoría apetecible, un litigio aborrecible», en Boletín de la Institución Fernán González, 232, Burgos, 2006, pp. 149-178.

109 ACCB. AC. LR 106, Cabildo del 18 de abril de 1757, folio 192, «Sobre que el panadero dé buen pan».
} 


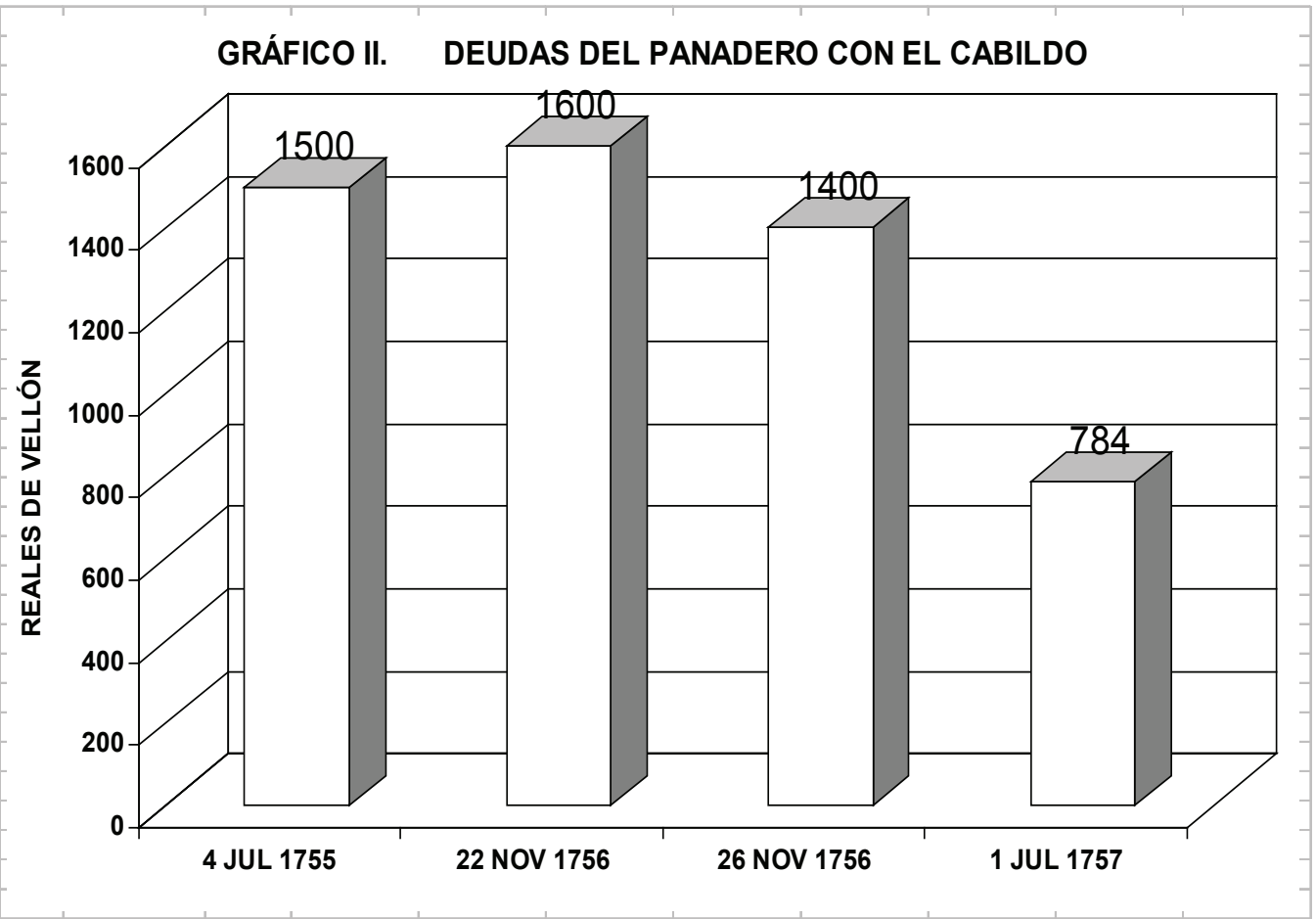

un hecho aislado. En julio de dicho año, el «Acerca del Panadero» era la comidilla de los capitulares fuera de la Catedral y en el propio Cabildo. No se trataba sólo de la cobranza de lo que debía -véase GRÁFICO II- sino, y especialmente, de que "procure dar pan de Calidad y Satisfazción». El pesimismo lo inundaba todo. Los prebendados llegaron a la conclusión de que «sólo pueden lograr de él buenas palabras y que alguno u ottro día dé Pan bueno». La cobranza de las deudas ya sabían que «es algo dificil» y aunque prometía «ir satisfaciendo poco a poco, contemplan estte efugio infructtuoso y que surtta poco efecto». Le dieron un mes de plazo, aunque en las circunstancias en que se encontraba la quiebra era inminente ${ }^{110}$.

El problema venía de lejos. En julio de 1755, ya se había detectado que en el proceso de compras de trigo se estaban produciendo desviaciones problemáticas, y en un doble sentido. Por una parte, dado que en la escritura con el panadero se estipulaba que se le darían «a coste y portte» 200 fanegas de trigo blanquillo. El $1^{\circ}$ de julio de 1755 se encontraba alcanzado en 91 fanegas y 17 panes, que había vendido a razón de 25

$\overline{110}$ ACCB. AC. LR 106, Cabildo del 1 de julio de 1757, folio 226. 
reales y 10 maravedíes, quedándole de aumento los despojos de panadería y 2 reales y 31 maravedíes más, por haber costado la fanega, con su intervención y ajuste, a 32 reales y 12 maravedíes. Por tanto, debía satisfacer 91 fanegas y 17 panes a 32 reales y 13 maravedíes, cargo de 1.000 reales que el panadero en la Mayordomía, "ofreciendo a aprontar con brevedad 500 Rs más»-véase GRÁFICO II-. Por otra, "Haviéndose comprado 524 fanegas y 3 zelemines de trigo Valenciano para el gasto que se reguló hasta nueba cosecha, deducidas las 260 fanegas y 9 zelemines deel gasto hecho hasta Julio y deel Alcance al Panadero, restan esistentes 295 fanegas y media, las 32 en harina y las demás en poder deel Sor Ramos; y reservando de ellas 80 o 90, que hasta nueba Cosecha se podrán gastar, el resto, si pareziese al Cavildo, se podrán beneficiar en trigo o en pan cocido, dando el Panadero el producto diario al Capellán [del número]». Las previsiones de compra de grano y de producción de pan presentaban, en efecto, unas trayectorias peligrosas no sólo en lo global sino también en lo particular. De alaga el panadero estaba alcanzado, a principios de julio, en 14 fanegas, "haviendo existentes en arina 50 fanegas, lo que se puede consumir o bien en el gasto de algunos Señores, si quieren proseguir con quenta privativa, o beneficiarlo en pan con la misma quenta diario sobre dha» ${ }^{11}$.

No sólo eran negligencias del panadero. El cabildo también llamó la atención a don Jacinto Pérez en lo tocante a previsión de compra y producto, «siendo necesario que para el gasto de un mes estén siempre en poder deel Panadero de 40 a 50 fanegas de trigo para labarlo, abañarlo, molerlo y cocerlo, para no experimentar nuebos alcanzes, [de forma que] se podrán enttregar las parttidas de trigo al Capellán que viviere en la Casa para que tenga Cuidado de tomar la quenta por Semanas y darla a los Señores Diputados por meses» ${ }^{12}$.

Un ejemplo de la deriva de la producción de pan lo hallamos en el Cabildo de 23 de junio de 1755, en el que se informa puntualmente sobre el panadero de la primera mitad del año -véase GRÁFICO III-. Debatir «Sobre la Panadería», y sus vicisitudes y problemáticas, se convirtió en un asunto habitual. Alarmaban, y mucho, los alcances y deudas del panadero y el destino del trigo existente. Se desea la "permanencia de estte proiectto» pero se exigía un "régimen más exactto en lo Subcesivo» y más información sobre las "patologías» advertidas en las compras, almacenamiento y fabricación de trigos y pan ${ }^{113}$.

En septiembre de 1755, siendo ya asiduo el tratar «Sobre [el] Pan de la Panadería, trigo y otras provisiones», los Diputados de Hacienda expusieron «que deel trigo comprado para el Surttimientto de la Panadería se hallaban existentes 160 fanegas de grano sin poder tener arbitrio de Venderse por no aver quien lo quiera y las dificultades de su Consumo en pan». Asimismo, «insinuaron se hazía preziso hazer prevenzión de trigo Blanquillo pues

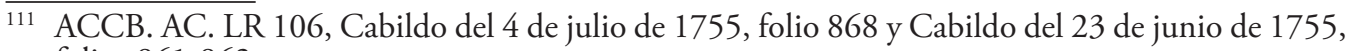
folios 861-862.

112 ACCB. AC. LR 106, Cabildo del 4 de julio de 1755, folio 868.

113 ACCB. AC. LR 106, Cabildo del 14 de junio de 1755, folio 861. 


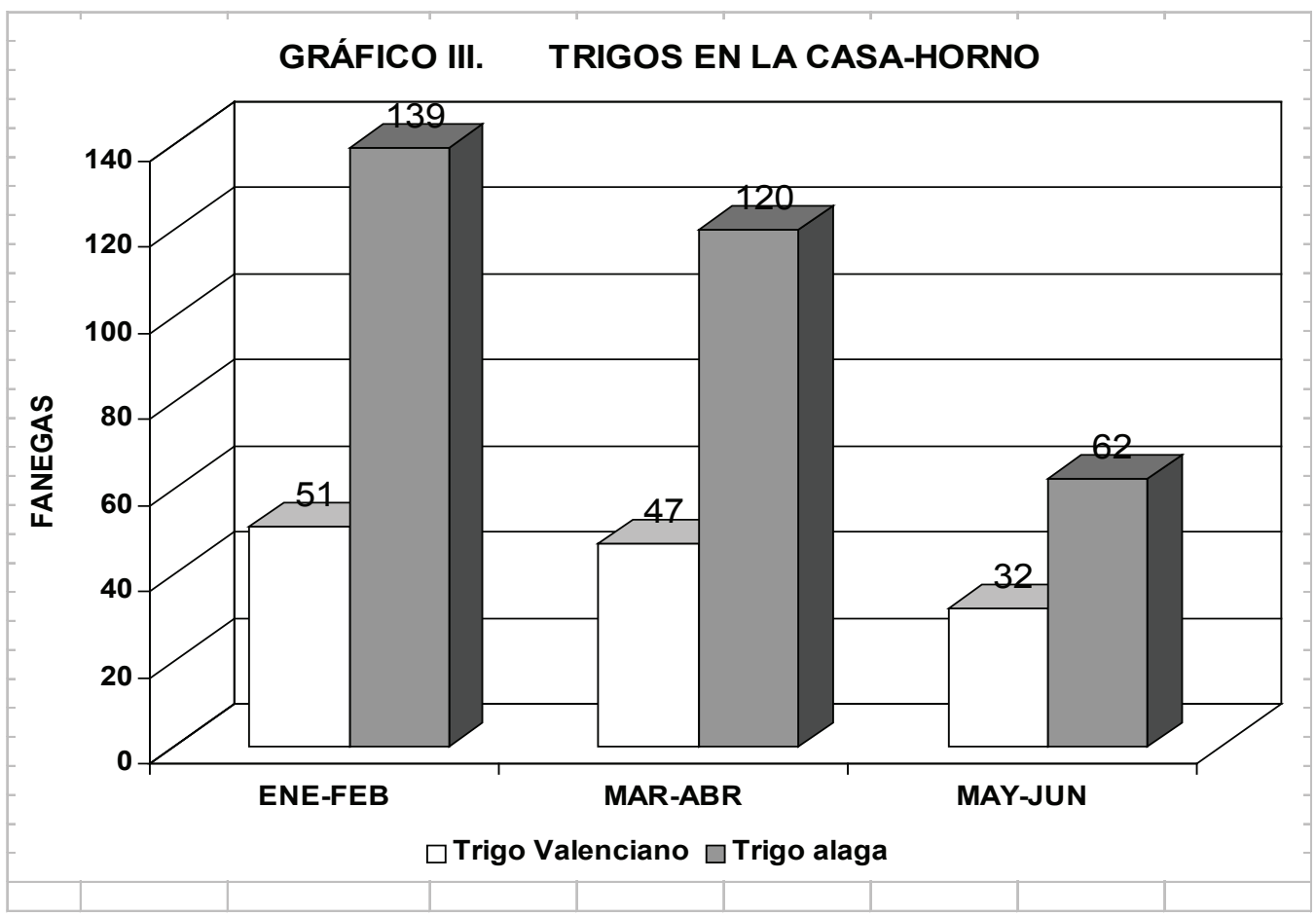

se podrá lograr oy con alguna Comodidad». La logística del panadeo fallaba estrepitosamente. ¿Qué hacer con el trigo sobrante? El Cabildo decidió hacer "Cómputo y Cáculo de lo que corresponda a cada Yndividuo y, rebasado lo que haya Consumido, se le repartta del sobrante a proporzión equitativamente y con Justificación» ${ }^{114}$. Es evidente que llegar a estos enjuagues suponía, en la práctica, asumir un fracaso sin paliativos en lo tocante al surtimiento directa del pan a los prebendados. Era preciso urgir al capellán responsable que extremara el cuidado «sobre la bondad del Pan», sobre su calidad, y «sobre que, por Meses, enttregue al Panadero, con quentta y Razón, lo que puede gastar, para precaver de estte modo qualquiera inconveniente que pueda ofrecerse en lo subzesibo» ${ }^{15}$.

Días después, el 14 de noviembre de 1755, los Diputados de Hacienda del Cabildo anunciaron que el panadero «conttinuará en dar Pan Valenziano hasta el Domingo y el Lunes daría prinzipio con el trigo Blanquillo, obligándose a dar 24 Panes en flor por Casa fanega». Ello modificaba el contenido de la Escritura de obligación. Era preciso o redactar nueva Escritura o efectuar una «adizión de estta Cláusula a la que tiene echa». En todo caso exigían que "zelen se esmere el Panadero y don Jacinto [Pérez] en promover dé este Pan

$\overline{114}$ ACCB. AC. LR 106, Cabildo del 22 de septiembre de 1755, folio 901.
115 ACCB. AC. LR 106, Cabildo del 22 de septiembre de 1755, folio 902. 
de la mejor Calidad» ${ }^{116}$. A todas luces, ninguno de los objetivos se consiguió a la postre, de manera que finalmente fue perentorio liquidar el abasto de pan con Fernando Zernuda y continuarlo, si fuera posible, con otra estrategia menos lesiva para los intereses de los prebendados.

Dos momentos puntuales delatan el fracaso inevitable. El 9 de junio de 1758, el capellán del número expuso que "para el Cuidado de la Panadería muda de Cassa y desea que se providenzie o vendiendo o mandando entregar a otro porzión de trigo blanquillo que tiene» ${ }^{117}$. Don Jacinto Pérez estaba harto de velar por un asunto insoluble. El 16 de mayo de 1760, el canónigo García Velarde «insinuó avía Sujetto que comprase los Zeazos (sic) que servían a la Panadería de V. S., que siendo del beneplácito del Cavildo pasaría a venderlos» ${ }^{118}$. En 1762, Francisco Martín asumía el arrendamiento de la casa por 9 años y 470 reales más 10 gallinas de alquiler al año, con la condición de que «si Su Señoría el Cavildo o por algún Señor Capitular se le diese trigo blanquillo ha de dar por cada fanega Veinte y tres panes de flor de lo mejor que se ponga en la Plaza, con la condición de llebarlo a las Casas de dhos Señores, y uno de mediano, como también de tener permanentemente el Zedazo y demás pertrechos de dho Horno, propio de dhos Señores, que ha de constar de Ynventario que se ha de hazer de ellos, los que concluido dho arriendo y no siguiendo con él los ha de entregar tales y tan buenos como los reciviese» ${ }^{19}$.

\section{A MODO DE CONCLUSIÓN}

La experiencia llevaba a cabo por el Cabildo Catedral de Burgos para abastecerse de pan a través de su propia casa-horno, supuso, en la práctica, un ejercicio de autonomía clerical frente a los poderes públicos, en especial frente al Concejo y los regidores perpetuos, con quienes, en aquellos ańos, mantenía un conflicto abierto con el cacao como telón de fondo. Aunque finalmente fracasada, en gran parte por la incompetencia del maestro panadero contratado para efectuar el panadeo, la tentativa tocaba una fibra sensible de las relaciones Iglesia-Estado en el devenir del siglo de la Ilustración ${ }^{120}$. La Catedral de Burgos, ante el cada vez más pronunciado acoso fiscal de la Administración borbónica y las desidias y desabastecimientos de los productos más esenciales, decidió apostar por ser, en la práctica, una «empresa» de servicios para sus

\footnotetext{
$\overline{116}$ ACCB. AC. LR 106, Cabildo del 14 de noviembre de 1755, folio 916.

117 ACCB. AC. LR 106, Cabildo del 9 de junio de 1758, folio 364.

118 ACCB. AC. LR 106, Cabildo del 16 de mayo de 1760, folio 705.

119 ACCB. Libros de Subsidio y Excusado y otros, Libro 90. Libro de Cabezas de casa, Casa no 195 (La Calera), folio 225.

120 Véase OLAECHEA, Rafael, «Relaciones entre Iglesia y Estado en el siglo de las luces», en ALBEROLA ROMÁ, Armando y LA PARRA, Ernesto (Eds.), La ilustración española, Alicante, Instituto Juan Gil-Albert, 1986, pp. 271-297.
} 
prebendados, ansiosos de buen pan, delicioso chocolate, carne abundante, luminoso aceite, vino nutritivo,...

Escapar de las omnipresentes estructuras logísticas del Concejo suponía adentrarse en complicadas fórmulas de liberalización, muy de moda en la época, antesalas del mundo capitalista posterior. La fabricación de pan en Burgos conoció intentos, como el analizado para el Cabildo Catedral, o el posterior de la tahona de la Compañía para el abasto de pan cocido (1779-1782), también tristemente fracasada, todas ellas basadas en una disrupción del sistema de obligación de los pueblos panaderos y en el desligamiento de los talleres artesanos, obsoletos y medievalizantes. El Cabildo quería degustar su propio pan, con harinas obtenidas en la trituración de sus trigos en el molino de su propiedad y hacer llegar a las viviendas de los prebendados hogazas de $2 \frac{1}{2} 2$ libras salidas de sus propios hornos. Poco tiempo tardó la realidad en amargar el ansiado pasado en libertad y con independencia.

Las relaciones entre el Cabildo Catedral y el Concejo de Burgos ${ }^{121}$ eran, en los años centrales del siglo XVIII, difíciles cuando no incluso espinosas, con las problemáticas devenidas por cuestiones de protocolo, de corte hacendístico, de cariz logístico, de sesgo tributario,... Desde el litigio gestado, en 1743, alrededor del Seminario de San Nicolás, tutorado por ambas instituciones, con el telón de fondo de quién sería su rector ${ }^{122}$, conflicto en el que se produjo un enfrentamiento abierto entre las redes de influencia clerical capitular y laical municipal entorno a si el deán Calderón de la Barca o el lectoral Prieto Bustamante ocuparía dicho puesto -obligados los regidores a tomar partido por uno u otro-, las polémicas fueron incrementándose. La existencia misma de un diezmo sobre los combustibles percibido por el Cabildo Catedral desde prácticamente su constitución y que el Concejo quería fulminar, aspecto ligado a la fiscalidad de los suministros de carbón y leña para el Cabildo ${ }^{123}$, era otro

121 Sobre este controvertido aspecto, véanse los análisis, propuestas y sugerencias, entre otros, de CÁNOVAS BOTÍA, Antonio, Auge y decadencia de una institución eclesial: el Cabildo Catedral de Murcia en el siglo XVIII. Iglesia y sociedad, Murcia, Universidad de Murcia, 1994, pp. 441-444. VILLACORTA RODRÍGUEZ, Tomás, El Cabildo Catedral de León. Estudio histórico-jurídico, siglo XII-XIX, León, Centro de Estudios e Investigación "San Isidoro», Caja de Ahorros y Monte de Piedad de León y Archivo Histórico Diocesano, 1974, pp. 528-538. BENITO AGUADO, Ma Teresa, La sociedad vitoriana en el siglo XVIII: El clero, espectador y protagonista, Bilbao, Universidad del País Vasco, 1986, pp. 78-84 y 241-314.QUINTANA ANDRÉS, Pedro C., A Dios rogando, y con el mazo dando. Fe, poder y jerarquía en la iglesia canaria. El Cabildo Catedral de Canarias entre 1483-1820, Las Palmas de Gran Canarias, Cabildo de Gran Canaria, 2003, pp. 723-744 y GARCÍA-CUEVAS VENTURA, José, El Cabildo catedralicio cordobés desde la Revolución a la Restauración (1788-1882), Córdoba, Universidad de Córdoba, 1996, pp. 161-164.

122 SANZ de la HIGUERA, Francisco, «Seminario de San Nicolás (Burgos, 1743): una rectoría apetecible, un litigio aborrecible», en Boletín de la Institución Fernán González, 232, Burgos, 2006, pp. 149-178.

123 SANZ de la HIGUERA, Francisco, «¿Diezmo sobre los combustibles? Cabildo, Concejo y Hacienda pública en el Burgos del Antiguo Régimen", en Historia, Instituciones, Documentos, 37, Sevilla, 2010, pp. 337-364. 
frente de turbulencia que se unía a los desencuentros entre ambas instituciones en torno a la logística del cacao, con un Cabildo Catedral que, al igual que hizo con lo referente al acceso al panadeo, había tomado el derrotero de abandonar la dependencia del Concejo para iniciar sus propias fórmulas de suministro ${ }^{124}$. Las presiones de la Intendencia y el Concejo -en realidad de la Administración borbónica- por «hermosean la ciudad, sus calles y su hábitat, y el incendio de cuatro casas de la calle La Calera, propiedad del Cabildo ${ }^{125}$, acentuaron, más si cabe, las agrias relaciones entre la más poderosa entidad eclesiástica y las más omnipotente institución de gobierno y de gestión de la ciudad.

124 SANZ de la HIGUERA, Francisco, «Clero catedralicio y consumo de chocolate en el Burgos del Setecientos», en Tiempos Modernos, Logroño -en proceso de evaluación por su Concejo de Redacción-.

125 SANZ de la HIGUERA, Francisco, «Una ardiente operación urbanística y crediticia. El incendio de las casas de la calle La Calera y el Cabildo Catedral de Burgos (1773-1776)", en Cuadernos de Estudios del Siglo XVIII, Oviedo -en fase de «información» y evaluación por el Consejo de Redacción-. 